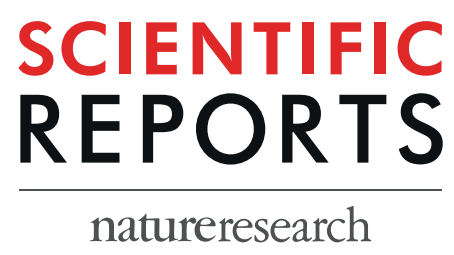

\title{
OPEN The selective GSK3 inhibitor, SAR502250, displays neuroprotective activity and attenuates behavioral impairments in models of neuropsychiatric symptoms of Alzheimer's disease in rodents
}

Guy Griebel ${ }^{1 *}$, Jeanne Stemmelin ${ }^{2}$, Mati Lopez-Grancha ${ }^{3}$, Denis Boulay ${ }^{4}$, Gerald Boquet ${ }^{5}$, Franck Slowinski ${ }^{6}$, Philippe Pichat ${ }^{7}$, Sandra Beeské ${ }^{8}$, Shinji Tanaka ${ }^{9}$, Akiko Mori ${ }^{9}$, Masatake Fujimura ${ }^{9}$ \& Junichi Eguchi ${ }^{9}$

Glycogen synthase kinase 3 (GSK3) has been identified as a promising target for the treatment of Alzheimer's disease (AD), where abnormal activation of this enzyme has been associated with hyperphosphorylation of tau proteins. This study describes the effects of the selective GSK3 inhibitor, SAR502250, in models of neuroprotection and neuropsychiatric symptoms (NPS) associated with AD. In P301L human tau transgenic mice, SAR502250 attenuated tau hyperphosphorylation in the cortex and spinal cord. SAR502250 prevented the increase in neuronal cell death in rat embryonic hippocampal neurons following application of the neurotoxic peptide, $A \beta_{25-35}$. In behavioral studies, SAR502250 improved the cognitive deficit in aged transgenic $A P P(S W) / T a u(V L W)$ mice or in adult mice after infusion of $A \beta_{25-35}$. It attenuated aggression in the mouse defense test battery and improved depressive-like state of mice in the chronic mild stress procedure after 4 weeks of treatment. Moreover, SAR502250 decreased hyperactivity produced by psychostimulants. In contrast, the drug failed to modify anxietyrelated behaviors or sensorimotor gating deficit. This profile confirms the neuroprotective effects of GSK3 inhibitors and suggests an additional potential in the treatment of some NPS associated with AD.

Neuropsychiatric symptoms (NPS) are frequently observed in patients with Alzheimer's disease (AD) and are being increasingly recognized as hallmarks of this condition and related dementias ${ }^{1}$. These symptoms range from aggression, anxiety, cognitive deficit, depression, disinhibition, irritability, sensorimotor deficit and sleep disorders with a global prevalence of 39 to 49 percent for the most frequent NPS ${ }^{2}$. The presence of NPS in the early stages of AD predicts disease progression ${ }^{3}$. In addition, there is only one approved drug for the treatment of NPS in AD in Europe and Canada, namely risperidone for the management of aggression. A range of medications, including monoaminergic antidepressants, benzodiazepine anxiolytics, cholinesterase inhibitors or the psychostimulant methylphenidate, have been occasionally used for the treatment of NPS in AD patients but they

\footnotetext{
${ }^{1}$ Sanofi, Strategy \& Business Development, Chilly-Mazarin, France. ${ }^{2}$ Sanofi R\&D, Global Project Management, Chilly-Mazarin, France. ${ }^{3}$ Sanofi R\&D, Rare and Neurologic Disease Research, Chilly-Mazarin, France. ${ }^{4}$ Sanofi R\&D, Translational In Vivo Models, Chilly-Mazarin, France. ${ }^{5}$ Sanofi R\&D, Integrated Planning and Operations, Project Planning Management, Chilly-Mazarin, France. ${ }^{6}$ Sanofi R\&D, Integrated Drug Discovery, Chilly-Mazarin, France. ${ }^{7}$ Sanofi R\&D, Integrated Planning and Operations Management, Chilly-Mazarin, France. ${ }^{8}$ Sanofi R\&D, Cardiovascular Diseases \& Metabolism, Chilly-Mazarin, France. ${ }^{9}$ Research Division, Mitsubishi Tanabe Pharma Corporation, Kamoshida-cho, Aoba-ku, Yokohama, Japan. *email: guy.griebel@sanofi.com
} 


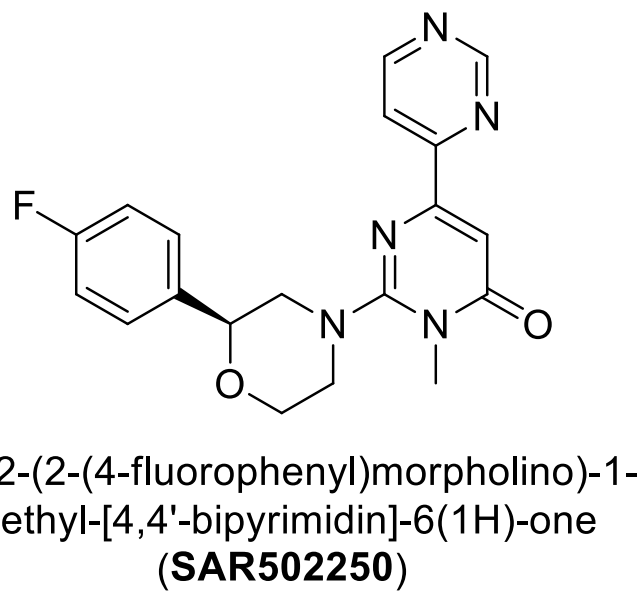

Figure 1. Chemical structure of SAR502250.

have demonstrated limited efficacy and sometimes poor compliance due to unwanted adverse effects (for a recent review, see ${ }^{1}$. As a result, there is renewed interest in finding more effective treatments for NPS in $\mathrm{AD}^{1}$.

A drug combining disease-modifying activity with NPS-reducing potential would represent an ideal therapy for the treatment of AD. Among the most interesting candidates bearing the potential of targeting the disease at its roots along with its associated NPS are glycogen synthase kinase-3 (GSK3) inhibitors. GSK3 which was discovered about 30 years ago is a serine/threonine protein kinase involved in a variety of cellular processes, e.g., microtubule dynamics, gene transcription and cell proliferation ${ }^{4-6}$. GSK3 is involved in AD progression, including pathophysiological formation of paired helical filament tau, an integral part of the deposits of neurofibrillary tangle responsible for disruption of neuronal function in this condition ${ }^{7}$. Hence, inhibiting this protein kinase has been suggested to be a potential strategy to treat patients suffering from $\mathrm{AD}$ ( $\mathrm{see}^{8,9}$ for two recent reviews). In preclinical models, lithium an early GSK3 inhibitor was found to reduce aspects of AD pathology, including tau phosphorylation and amyloid production both in vitro and in vivo ${ }^{7,10-12}$. During the last decade, several selective, orally active and brain penetrant GSK3 inhibitors have been identified. They have demonstrated neuroprotective activity by inhibiting hyperphosphorylation of tau protein in cell-based assays (for a recent review, see $^{9}$ ).

Evidence supporting the idea that GSK3 inhibitors may have an additional potential for alleviating NPS originates from several studies in animals showing that GSK3 inhibition may contribute to the action of antidepressants $^{13-17}$ and antipsychotics ${ }^{18-23}$. This idea is additionally substantiated by studies with selective GSK3 inhibitors, which showed that these drugs produce antidepressant-like effects in animal models ${ }^{24-27}$. Evidence supporting a therapeutic potential of these molecules in other NPS, such as anxiety or agitation has not been well established.

In this context, the objective of this study was to characterize the behavioral effects of the selective ATP competitive GSK3 inhibitor, SAR502250 (a.k.a. UDA-680) (Fig. 1), in models related to certain aspects of NPS, including agitation, aggression, anxiety, cognitive and sensorimotor deficits, and depression. The compound was additionally tested for its neuroprotective potential in in vitro/vivo assays of cell death and tau hyperphosphorylation. SAR502250 was described previously as a potent, selective and competitive inhibitor of mouse and human GSK3 ( $\mathrm{IC}_{50}=12 \mathrm{nM}$ in both species), with excellent brain permeability in the mouse (brain/plasma ratio: 2.7 after 2 hours $)^{28,29}$.

\section{Methods and Materials}

Ethics statement. All experimental procedures described herein were carried out in accordance with the "Guide and Care" and were approved by the Animal Ethics Committee of Sanofi and Institutional Animal Care and Use Committee of Research Laboratories, Mitsubishi Tanabe Pharma Corporation.

Animals. Animals had access to food and water ad libitum with a 12-h light/dark cycle (lights on at 7:00 a.m.). The following species and strains were used: (1) mice: BALB/c, C57BL/6J, CD1, OF1 and Swiss (Charles River Laboratories, Janvier Labs, Le Genest Saint Isle, France or Iffa Credo, Les Oncins, France), APP (SW)/Tau (VLW) and P301L human tau transgenic mice (Taconic Biosciences); (2) Rats: Wistar and Sprague-Dawley (Iffa Credo) (see below for further details). Different species and strains were used on the basis of pilot experiments, which demonstrated that some species and/or strains are more suitable than others in certain models. Tests were performed during the light (day) cycle.

Drugs. SAR502250 (Sanofi Medicinal Chemistry), amphetamine, fluoxetine, lithium chloride, phencyclidine (PCP) (Sigma-Aldrich, Saint-Quentin Fallavier, France) were dissolved or suspended in distilled water with $0.6 \%$ methylcellulose and the addition of 5\% Tween 80 (Sigma-Aldrich) or 2\% Cremophor in in vivo studies and suspended in dimethylsulfoxyde (DMSO) at $10 \mathrm{mM}$ in in vitro experiments. Doses refer to the weight of the free base. SAR502250 was administered orally (per os, p.o.) in the behavioral tests with the exception of the chronic mild stress procedure where it was administered intraperitoneally (i.p.). This administration route was chosen because exploratory experiments showed that it is more suitable in this test than the p.o. route. Different treatment schedules were chosen because some of the procedures used required repeated administration to observe a drug effect 
(e.g. chronic mild stress). The amount of vehicle was adjusted to be the same for all the doses and controls. Volume of administration was 10 or $20 \mathrm{ml} / \mathrm{kg}$ in mice, 1 or $5 \mathrm{ml} / \mathrm{kg}$ in rats. All drug solutions were prepared fresh daily.

Characterization of SAR502250 in tests predictive of therapeutic activity against Alzheimer's disease. Effect of SAR502250 on A $\beta_{25-35}$-induced cell death in rat embryonic neurons. Male and female E18 Wistar rats were used. Embryonic hippocampal cells were cultured in neurobasal medium (Thermo Fisher Scientific) supplemented with glutamine (Thermo Fisher Scientific) and B27 supplement (Thermo Fisher Scientific) for 6 days. Cells were treated with drugs ( $\mathrm{LiCl}$ or SAR502250) and A $\beta_{25-35}$ (BACHEM) for 36 hours. After the incubation period, cell viability was measured by MTS assay (Promega). Statistical differences between the groups were determined by Dunnett's multiple comparison test.

Effect of SAR502250 on tau hyperphosphorylation $\left(S_{396}\right)$ in vivo in P301L human tau transgenic mice. Threemonth-old female P301L human tau transgenic mice (JNPL3), having an average weight of $32 \mathrm{~g}$ at the time of testing were used. They received a single dose of SAR502250 $(1,3,10,30$ and $100 \mathrm{mg} / \mathrm{kg} / \mathrm{d})$ by oral route. One hour after the administration, brains and spinal cords were rapidly dissected and quickly frozen. Tissue was homogenized with homogenization buffer (62.5 mM Tris-HCl pH 6.8, 2.3\% SDS, 1 mM EDTA, 1 mM EGTA, 1 mM DTT, Protease inhibitor cocktail (Sigma-Aldrich), Phosphatase inhibitor cocktail (Roche Diagnostics). Homogenized sample was boiled for $5 \mathrm{~min}$ and centrifuged at $15,000 \mathrm{x}$ g for $15 \mathrm{~min}$. Supernatant was collected and protein concentration was measured by DC protein assay (Bio Rad). $10 \mu \mathrm{g}$ of samples were applied on 10\% SDS-PAGE and transferred onto nitrocellulose membranes. Total human tau protein and phosphorylated $\left(\mathrm{S}_{396}\right)$ tau protein was evaluated by western-blotting labelling with TauN (BD Transduction) and PS396 (Thermo Fisher Scientific) antibodies respectively. Each band was visualized with ECL kit (Amersham Bioscience) and detected with LAS 1000 (Fuji Film).

Effects of SAR502250 on short-term visual episodic memory deficit following the central infusion of A $325-35$ peptide using the object recognition test (ORT) in mice. Male Swiss mice weighing 20-22 g, 4-5-week-old at the beginning of the experiment were used. The procedure was the same as described by Griebel et al..$^{30}$ and was based on that originally described by Ennaceur and Delacour ${ }^{31}$ in rats and adapted for use in mice. The apparatus consisted of a uniformly lit (20 lux) PVC enclosure $(52 \mathrm{~L} \times 52 \mathrm{~W} \times 40 \mathrm{H} \mathrm{cm}$ ) with a video camera positioned $160 \mathrm{~cm}$ above the bench. The observer was located in an adjacent room fitted with a video monitoring system. The experiment consisted of 3 sessions. During the first session (context habituation), the subjects were allowed 2 min to become acquainted with the apparatus. Time in active locomotion was manually recorded with a precision of $\pm 0.1 \mathrm{sec}$. The animals were again placed in the enclosure 24 hours thereafter for the second (acquisition) session, during which they were exposed to a pair of identical objects $(5.5 \mathrm{~L} \times 2 \mathrm{~L} \times 3.3 \mathrm{H} \mathrm{cm}$ grey metal triangle or $3 \mathrm{~L} \times 3 \mathrm{~W} \times 3 \mathrm{H} \mathrm{cm}$ plastic pyramid) placed $10 \mathrm{~cm}$ away from the 2 opposite corners of the back wall.

Animals were left in the enclosure for the amount of time necessary to spend at most 15 seconds exploring these 2 objects within a 5 min timeframe. Animals were removed from the cage once they had reached the 15 -second exploration time. Exploration of an object was defined as the animal having its head within $1 \mathrm{~cm}$ of the object while looking at it, sniffing it or touching it. Any animal spending less than 15 seconds exploring the 2 objects within $5 \mathrm{~min}$ was eliminated from the study. Two different sets of objects were used to allow for cleaning between 2 consecutive animals in order to minimize olfactory cueing. Combinations of orders of presentation and locations of objects were counterbalanced to reduce potential biases owing to spatial or object preferences. During the third (recall) session, animals were exposed to the familiar (i.e. presented during the previous acquisition session) and a novel (i.e. never presented before) object for $4 \mathrm{~min}$, and the time spent exploring each object was recorded. Any animal spending less than 3 seconds exploring both objects was discarded from the study. This third session took place one hour following the second session.

The peptide solution (BACHEM, Switzerland) was incubated at $37^{\circ} \mathrm{C}$ for 4 days prior to the administration. $3 \mu \mathrm{L}$ of the $\mathrm{A} \beta_{25-35}$ solution ( $9 \mathrm{nM}$ of peptide) were slowly injected into the lateral ventricle of isoflurane-anesthetised mice. Injection was done manually, without the help of a stereotaxic apparatus. Accuracy of the injection was checked in a preliminary experiment using indian ink and reached a $95 \%$ confidence. The control peptide (scrambled $\mathrm{A} \beta_{25-35}$ ) consisted of the same sequence of amino acids, but in a random order. It was prepared and administered following the same procedure. Ten days after $\mathrm{A} \beta_{25-35}$ administration, animals were tested in the ORT. SAR502250 was injected acutely, p.o. $60 \mathrm{~min}$ before the acquisition session. The data were expressed as ratio "new/(familiar + new $) \times 100$ ", representing the recognition index $(\mathrm{RI})$, and analysed using a Kruskal-Wallis multiple comparisons test. Eight to ten animals per group were used.

Effects of SAR502250 on short-term visual episodic memory deficit in APP (SW)/Tau (VLW) mice using the ORT. The procedure was the same as described by Griebel et al. ${ }^{30}$. Six-month-old male APP (SW)/Tau (VLW) mice and their non-transgenic wild-type littermates were used for the study. Both were backcrossed to C57BL/6J mice and then crossed together to generate double transgenic mice co-expressing both transgenes on a C57BL/6J genetic background. The experimental setup is based on that described in the previous paragraph with slight modifications. Briefly, in the first session, mice were allowed to become familiar with the experimental environment for 2 minutes. Time spent in activity was measured. Twenty-four hours later, mice were again placed in the enclosure in the presence of two identical objects until they had explored them for a total duration of $15 \mathrm{~s}$. After a forgetting interval of $60 \mathrm{~min}$, mice were placed again in the enclosure with a previously presented object and a new object for $4 \mathrm{~min}$. Time spent exploring the familiar and the new objects were recorded. SAR502250 was administered orally once-a-day for 7 weeks. The last administration was given 30 minutes prior to the second 
session (i.e. acquisition). The RI was analysed using one-way ANOVA using a fixed factor of treatment or genotype and complementary post hoc (Dunnett) tests were performed. Seven to eleven animals per group were used.

Characterization of SAR502250 in tests predictive of therapeutic activity against psychiatric symptoms. To investigate potential effects of SAR502250 in comorbid symptoms of AD, we used wild-type animals/species, which were found to be more suitable than the pharmacological or transgenic models of AD in the current experimental procedures.

Depression. Effects of SAR502250 in the differential reinforcement of low rate-72s (DRL-72s) procedure in rats. The procedure was the same as described by Louis et al. ${ }^{32}$. Male Wistar rats (10-week-old) were singly housed with ad libitum access to water except during operant sessions. Their weight was kept at $450 \pm 50 \mathrm{~g}$ by feeding with $20 \mathrm{~g}$ of food chow given at the end of the day and over the weekend. The experiments were carried out in eight identical rat operant chambers (Med Associates, East Fairfield, VT, USA), each fitted with a $2.8 \mathrm{~W}$ overhead house light and a stainless-steel rods floor. A $4.8 \times 1.9 \mathrm{~cm}$ lever was positioned on the right side of a food tray, which was connected to a food pellets ( $45 \mathrm{mg}$, Formula P, Noyes, Research Diets, New Jersey, USA) dispenser. Each operant chamber was enclosed in a ventilated and sound-attenuating cubicle; all events were recorded and controlled by the 'Med-PC' software.

Acquisition of the Operant Behavior: Rats were first trained ( 5 days a week) in daily 30 min sessions to press a lever to obtain a food pellet under a continuous reinforcement-fixed time $60 \mathrm{~s}$ concurrent schedule (i.e. if the rat did not press the lever within $60 \mathrm{~s}$, a reinforcement was automatically delivered). When rats obtained at least 100 pellets per training session, they were subjected to a differential reinforcement of low-rate (DRL) $15 \mathrm{~s} \mathrm{schedule.} \mathrm{More}$ explicitly, a lever-press occurring before a delay of $15 \mathrm{~s}$ had elapsed was not rewarded and the timer was reset to $0 \mathrm{~s}$ for a further $15 \mathrm{~s}$ cycle. Session duration of these DRL sessions was set to $60 \mathrm{~min}$. Across successive DRL sessions, the timing of the DRL schedule was progressively increased from 15 to $30 \mathrm{~s}$ to the final timing of $72 \mathrm{~s}$. In order to acquaint them to the i.p. injection procedure, rats were injected with saline $30 \mathrm{~min}$ pre-session once they attained the DRL-72 s stage. Once performance had stabilized (ie less than $10 \%$ variation of total number of responses during six consecutive DRL-72 s vehicle sessions, and less than seven reinforcers per session), rats were subjected to pharmacological challenge sessions. Each rat received three drug treatments, with doses administered in a mixed order. For a given drug treatment, control values were calculated by averaging the performance of all vehicle sessions immediately preceding all drug sessions. Furthermore, a stability criterion (less than $10 \%$ variation of total number of responses between the vehicle session immediately before the drug session and the six vehicle sessions preceding the start of the pharmacological study: vide supra) was in effect in-between each drug session. Fluoxetine or the appropriate vehicle was administered i.p. 30 min pre-session, and SAR502250 was administered p.o. 60 min pre-session.

Data: The following parameters were automatically recorded by the Med-PC software: the total number of lever-presses emitted during the session, the number of food pellets obtained (i.e. the number of reinforced responses), and the inter-response time (IRT, the time elapsed between two lever-presses ${ }^{33}$ ). IRTs were subsequently split into nine bins (IRT bin (0-12 s), IRT bin (13-24 s), IRT bin (85-96 s), and IRT bin (49-96s)). From these raw data, the percentage of lever-presses emitted in each of the nine $12 \mathrm{~s}$ bins and the percentage of lever-presses reinforced were calculated using a Macro procedure with the Excel software (percentages were calculated as a function of the total number of lever-presses emitted during the session). The percentages of lever-presses during two IRT bins in particular were analyzed: (1) the IRT bin (0-12s), corresponding to the 'burst responses' and shown to be sensitive to benzodiazepine-like compounds ${ }^{33}$; (2) the IRT bin (49-96s), as it has been shown to be particularly sensitive to antidepressant drugs ${ }^{34}$.

Statistical analysis: The percentage of lever-presses emitted in bins (0-12s) and (49-96s), the percentage of lever-presses reinforced, and the total number of lever-presses were analyzed with a Friedman's test, followed by post hoc tests with a Dunn's correction factor for a comparison between drug and control (vehicle-treated) groups. Statistical analyses were performed with the SAS system 8.2 (SAS Institute Inc., Cary, NC, USA). Eight animals per group were used

Effects of SAR502250 in the chronic mild stress (CMS) test in mice. Male BALB/c mice weighing 24-29g and 5-6-week-old at the beginning of the experiment were used. Earlier studies demonstrated that this strain is particularly suitable for investigating the antidepressant-like effects of drugs in this model ${ }^{35}$. The CMS protocol is based on that used by Griebel et al ${ }^{36}$ and consists of the sequential application of a variety of mild stressors, including restraint, forced swimming in warm $\left(35^{\circ} \mathrm{C}\right)$ water, water and/or food deprivation, pairing with another stressed animal, each for a period of between 2 and 24 hours. The CMS procedure lasted 43 days. The physical state was measured according to a physical state scale attributing 3 points to well-groomed and clean animals, 2 points to animals with disorganized coat and 1 point to animals showing loss of fur and dirty fur, once-a-week over the 42-day CMS period. The administration of SAR502250 (30 mg/kg, i.p., once-a-day), fluoxetine (10 mg/ $\mathrm{kg}$, i.p., once-a-day) or lithium chloride $(100 \mathrm{mg} / \mathrm{kg}$, i.p., once-a-day) started 15 days after the beginning of the stress exposure and lasted until the CMS was completed (in total, 28 days of treatment).

Physical state data (expressed on a physical state scale from 1 to 3 ) from control stressed and unstressed animals were analyzed for each week of the CMS by a Wilcoxon test. Subsequently, physical state data from the 3 groups of stressed/treated animals were compared using a Kruskal-Wallis test followed by Kruskal-Wallis one-sided upper multiple comparisons tests with Bonferroni-Holm correction versus stressed control group (as increases in physical data scores are expected for mice treated with either fluoxetine, lithium chloride or SAR502250). Twenty animals per group were used.

Anxiety. Effects of SAR502250 in the mouse defense test battery (MTDB). Ten-week-old male OF1 mice weighing $40-55 \mathrm{~g}$ were used. Previous studies showed that this strain is particularly suitable for investigating the 
anxiolytic-like effects of drugs in this model ${ }^{37}$. The test was conducted in an oval runway as described by Griebel $e t$ al. ${ }^{38}$. Pretest: Sixty minutes after p.o. administration of SAR502250 (10,30 and $\left.100 \mathrm{mg} / \mathrm{kg}\right)$, lithium chloride $(50,100$ and $200 \mathrm{mg} / \mathrm{kg}$ ) and diazepam $(1,3$ and $10 \mathrm{mg} / \mathrm{kg}$ ), the mouse was placed into the runway for a 3-min familiarization period, in which locomotor activity (number of line crossings) was recorded. The rat avoidance test: Immediately after the 3-min familiarization period, the experimenter introduced a hand-held dead male Long Evans rat (370$375 \mathrm{~g}, 10$-week-old, killed by CO2 inhalation just before the beginning of the experiment) 5 times at one end of the runway and brought up to the mouse at a speed of approximately $0.5 \mathrm{~m} / \mathrm{s}$. Approach was terminated when contact with the mouse was made or the mouse ran away from the approaching rat. Flight was measured by the number of avoidances of 5 trials. Chase/flight test: The rat was then brought up to the mouse at a speed of approximately $2 \mathrm{~m} / \mathrm{s}$. A constant distance of 2 meters separated the rat and the mouse when the rat was introduced in the runway. Risk assessment was given by a measure of the number of stops (pauses in movement). The rat was removed after the chase was completed. Forced contact in the straight alley: By closing 2 doors $(60 \mathrm{~cm}$ distant from each other), the runway was then converted to a straight alley in which the mouse was confined. The experimenter brought the rat into contact with the mouse in the straight alley. Approaches were directed quickly (within 1 second) towards the rat's head. For each such contact, defensive aggression was measured by the number of bites by the mouse to the rat. Data concerning locomotor activity (number of line crossings), flight (number of avoidances), risk assessment (number of stops) and defensive aggression (number of bites) were subjected to analysis. Data were either assessed using a Student's t-test (diazepam) or a one-way ANOVA (SAR502250), or with the non-parametric tests, Wilcoxon (diazepam) or Kruskal-Wallis followed in case of significant effects by post-hoc one-sided lower Kruskal-Wallis multiple comparison tests versus respective control groups, as decreases in the different variables (number of avoidances, stops and bites) were expected for treated groups (SAR502250). Eight to eleven animals per group were used

Agitation. Effects of SAR502250 on hyperactivity induced by amphetamine in mice or by PCP in PCP-sensitized rat. In the first experiment, Male Swiss mice (22-26 g, 5-6-week-old) were orally pretreated with SAR502250 $(10,30$ and $60 \mathrm{mg} / \mathrm{kg})$ or vehicle, followed $30 \mathrm{~min}$ later by a challenge administration of vehicle or amphetamine at $2 \mathrm{mg} / \mathrm{kg}$, i.p. Immediately thereafter, they were placed in the activity cages devices $(20 \mathrm{~cm}$ diameter, $9.5 \mathrm{~cm}$ height, Apelex, France) and locomotor activity was recorded for a period of $30 \mathrm{~min}$. In the second experiment, Male Sprague-Dawley rats (80-100 g, 5-week-old) were administered PCP at $10 \mathrm{mg} / \mathrm{kg}$, i.p. for 5 consecutive days. Three days later, they were habituated to the activity cages $(38 \times 38 \times 25 \mathrm{~cm}$ high) for 60 minutes, before receiving an oral administration of SAR502250 (3, 10 and $30 \mathrm{mg} / \mathrm{kg})$. They were immediately replaced in the activity cage for further 30 minutes (in order to test for potential motor side-effects of SAR502250), and finally they received an acute challenge dose of PCP at $1.5 \mathrm{mg} / \mathrm{kg}$, i.p. before being replaced in the activity cages for a last $30 \mathrm{~min}-$ utes period. In summary, locomotor activity was recorded for 2 hours (habituation $60 \mathrm{~min}+$ treatment-period $30 \mathrm{~min}+$ post-challenge period $30 \mathrm{~min}$ ). Statistical analyses were performed using SAS V8.2 software (SAS Institute, Cary, NC, USA). The number of light beam breaks (motility count) recorded were analyzed using one-way ANOVAs using a fixed factor of challenge or genotype and complementary post hoc (Newman-Keuls) tests were performed. Nine to ten animals per group were used.

Sensorimotor gating deficit. Prepulse inhibition (PPI) deficit in Wistar rats. Male Wistar Rats (260300 g, 7-8-week-old) were tested in startle boxes (Med Associates, East Fairfield, VT, USA). The startle reflex was detected via a piezoelectric transducer situated below the startle platform and recorded via a computer. Rats were placed into a restraint cylinder $(8 \times 19 \mathrm{~cm})$ fixed on top of the startle platform. On the first day of the experiment, they were evaluated for their spontaneous PPI to distribute rats across the groups with similar-relatively low levels of PPI before pharmacological testing performed a day after. In order to test PPI abilities, rats were subjected to an initial habituation session that started with a 5-min adaptation period with a background white noise of $65 \mathrm{~dB}$, followed by five pulse stimuli to accustom the rats to the startling pulses ( $120 \mathrm{db}, 50 \mathrm{~ms}$ duration, inter-pulse 10 to 15 seconds), but these startling responses were excluded from the data analysis. Then, rats were submitted to a session of 40 trials of randomized paired "Pre-Pulse $(20 \mathrm{~ms}$ duration: $65 ; 72 ; 79 ; 85 \mathrm{~dB})-$ Pulse $(120 \mathrm{~dB}, 50 \mathrm{~ms}$ duration)" stimuli with a $40 \mathrm{~ms}$ of time delay preceding the pulse and with an inter-trial time (null period) of 10 to 15 seconds. During the null period, there was no presentation of acoustic stimulus with the exception of the background noise $(65 \mathrm{~dB})$. Prepulse inhibition was calculated for each rat, from averaged startle amplitudes for each of the three prepulse intensities across all test trials. The percentage of pre-pulse inhibition (expressed as percentage) was calculated as follows: (Startle amplitude following pulse - Startle amplitude following prepulse) $* 100$ / Startle amplitude following pulse $=\%$ of PPI. On day 2 , for pharmacological studies, rats were subjected to the same procedure as day 1 but were distributed (Latin square randomization) in five pharmacological distinct groups, in order to obtain similar average levels of PPI between groups, before testing. Each group was tested with either vehicle, clozapine $(10 \mathrm{mg} / \mathrm{kg})$ or SAR502250 (3, 10 and $30 \mathrm{mg} / \mathrm{kg})$, which was administered orally $60 \mathrm{~min}$ prior to testing. Sixteen to nineteen animals per group were used. The data were analyzed with a Kruskal-Wallis test followed in case of significant effects by post-hoc Kruskal-Wallis multiple comparison tests versus respective control groups. For additional details on the procedure, $\operatorname{see}^{39}$.

Results

Characterization of SAR502250 in tests predictive of therapeutic activity against Alzheimer's disease. Effect of SAR502250 on $A \beta_{25-35}$-induced cell death in rat embryonic neurons. The $\beta$-amyloid fragment $A \beta_{25-35}(20 \mu \mathrm{M})$ significantly increased cell death in rat embryonic hippocampal neurons (t-test: $\left.\mathrm{P}<0.01\right)$. This effect was attenuated significantly by SAR502250 at $100 \mathrm{nM}$ and $1 \mu \mathrm{M}(\mathrm{P}<0.01)$, and by lithium at 1 and $10 \mathrm{mM}(\mathrm{P}<0.05)$ (Fig. 2). 


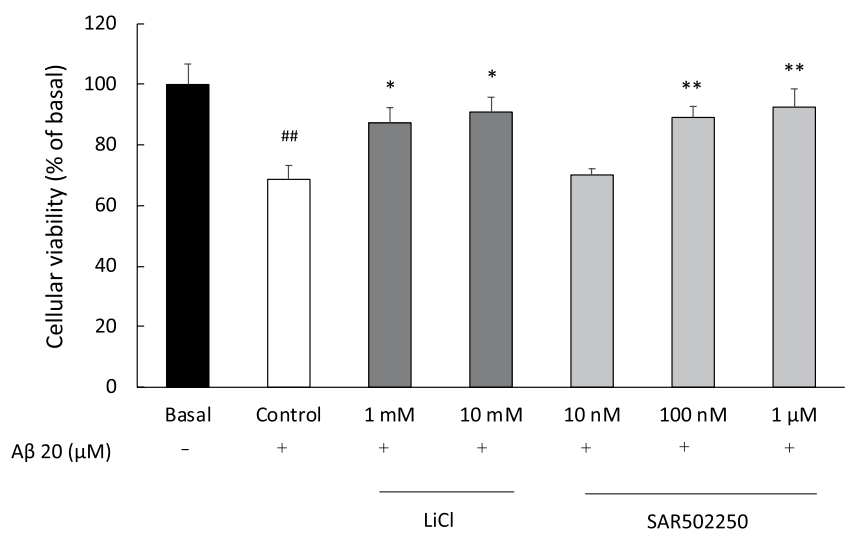

Figure 2. Effects of increasing concentrations of SAR502250 and lithium on $A \beta_{25-35}$-induced cell death in rat embryonic hippocampal neurons. Cells were treated with the experimental drugs and $A \beta_{25-35}$ for 36 hours. Data represent mean $\pm \mathrm{SEM} .{ }^{\# \#} \mathrm{P}<0.01$ (vs Basal, t-test); ${ }^{*} \mathrm{P}<0.05, * * \mathrm{P}<0.01$ (vs Control, Dunnett). $\mathrm{N}=6$.
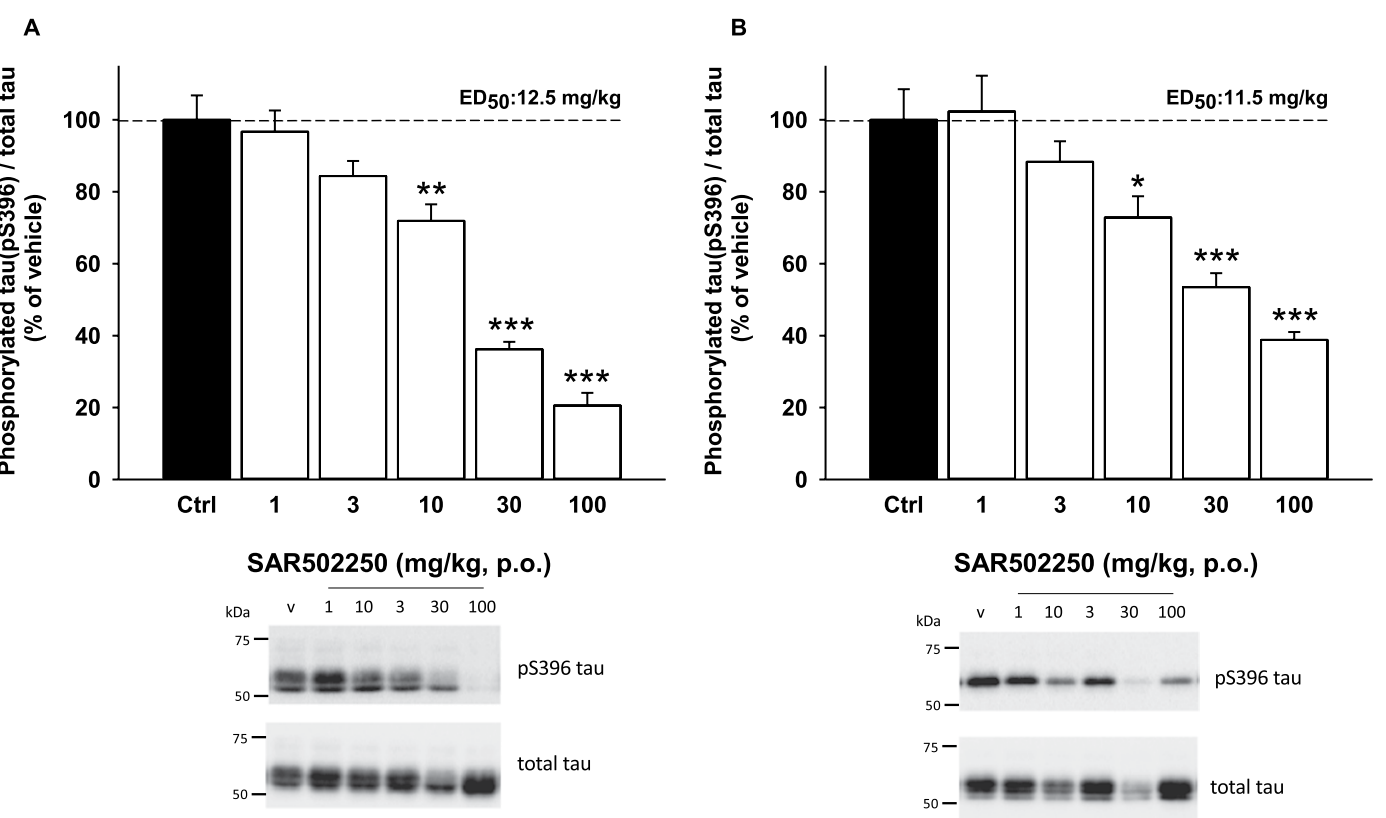

Figure 3. Effect of increasing doses of SAR502250 on tau hyperphosphorylation $\left(\mathrm{S}_{396}\right)$ in the cortex $($ A) and spinal cord (B) of P301L human tau transgenic mice. Time of administration was 60 minutes. Data represent mean + SEM. $* \mathrm{P}<0.05, * * \mathrm{P}<0.01$ and $* * * \mathrm{P}<0.01$ (vs Ctrl, Kruskal-Wallis). Blots cropped from different parts of the same gel are shown. Full-length blots are shown in Fig. S1. N=6.

Effect of SAR502250 on tau phosphorylation $\left(S_{396}\right)$ in vivo in P301L human tau transgenic mice. SAR502250 attenuated dose-dependently tau phosphorylation in the cortex $[\mathrm{F}(5,30)=47,35, \mathrm{P}<0.0001 ;$ Fig. 3A $]$ and spinal cord $[\mathrm{F}(5,30)=15.41, \mathrm{P}<0.0001$; Fig. $3 \mathrm{~B}]$ of transgenic mice expressing P301L tau. Post-hoc statistical analyses showed that these effects were significant from $10 \mathrm{mg} / \mathrm{kg}$ in both structures, with $\mathrm{ED}_{50 \mathrm{~s}}$ of 12.5 and $11.5 \mathrm{mg} / \mathrm{kg}$, respectively.

Effects of SAR502250 on short-term visual episodic memory deficit following the central infusion of $A \beta_{25-35}$ peptide using the object recognition test (ORT) in mice. Mice that received the scrambled $\mathrm{A} \beta_{25-35}$ peptide spent more time investigating the novel object [ $17.61 \mathrm{vs} 8.77 \mathrm{~s}$, recognition index $(\mathrm{RI})=67.2$; Fig. $4 \mathrm{~A}$ ], an effect which was abolished by the infusion of $A \beta_{25-35}$ [10.26 vs $\left.10.15 \mathrm{~s}, \mathrm{RI}=51\right]$. SAR502250, administered at 10 and $30 \mathrm{mg} / \mathrm{kg}$ before the acquisition session, significantly $\left(\chi^{2}=6.72, \mathrm{P}=0.03\right)$ restored this preferential investigation [ $10 \mathrm{mg} / \mathrm{kg}: 13 \mathrm{vs}$ $8.59 \mathrm{~s}, \mathrm{RI}=58.41 ; 30 \mathrm{mg} / \mathrm{kg}: 12.79$ vs $8.26 \mathrm{~s}, \mathrm{RI}=60.74$ ] (Fig. $4 \mathrm{~A})$.

Effects of SAR502250 on short-term visual episodic memory deficit in APP (SW)/Tau (VLW) mice using the ORT. Wild-type mice spent more time investigating the novel object [ $8.4 \mathrm{vs} 4.8 \mathrm{~s}, \mathrm{RI}=65.02$; Fig. $4 \mathrm{~B}$ ]. This preference for the novel object was not observed in APP (SW)/Tau (VLW) mice [8.4 vs $8.4 \mathrm{~s}, \mathrm{RI}=50.07]$. SAR502250, administered to transgenic animals at 10 and $30 \mathrm{mg} / \mathrm{kg}$ for 7 weeks, significantly $[\mathrm{F}(3,55)=3.64, \mathrm{P}=0.018]$ 

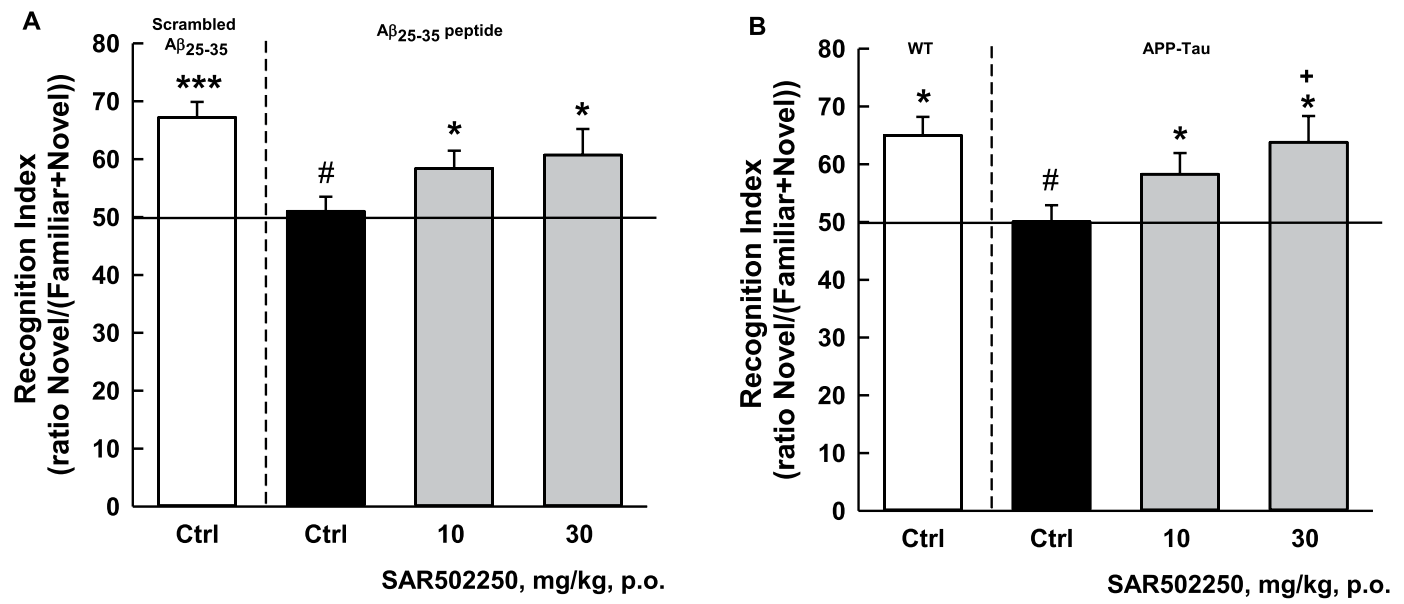

Figure 4. Effects of SAR502250 on short-term visual episodic memory deficit following the central infusion of $A \beta_{25-35}$ peptide in Swiss mice. The vehicle or the drug was given 60 min before the acquisition session (A) or in APP (SW)/Tau (VLW) mice (B) using the novel object recognition test. The vehicle or the drug was administered once-a-day for 7 weeks. The last administration was given 30 minutes prior to the second session. Data are expressed as recognition index + SEM. $* \mathrm{P}<0.05$ and $* * * \mathrm{P}<0.001$ (vs. chance level); ${ }^{*} \mathrm{P}<0.05$ (vs. Scrambled or WT); ${ }^{+} \mathrm{P}<0.05$ (vs. Ctrl APP-Tau) (Kruskal-Wallis or Dunnett). $\mathrm{N}=7-11$.

\begin{tabular}{|c|c|c|c|c|c|}
\hline Drugs & $\begin{array}{l}\text { Doses } \\
(\mathrm{mg} / \mathrm{kg})\end{array}$ & $\begin{array}{l}\text { Percentage bin } \\
(48-96 s)\end{array}$ & $\begin{array}{l}\text { Percentage reinforced } \\
\text { presses }\end{array}$ & $\begin{array}{l}\text { Percentage bin } \\
(0-12 s)\end{array}$ & Total presses \\
\hline Fluoxetine & 0 & $17.29 \pm 3.38$ & $2.80 \pm 0.60$ & $17.03 \pm 2.58$ & $117.72 \pm 8.80$ \\
\hline \multirow{3}{*}{ (i.p.) } & 2.5 & $19.36 \pm 3.87$ & $4.47 \pm 1.13$ & $15.87 \pm 1.26$ & $109.33 \pm 7.78$ \\
\hline & 5 & $23.23 \pm 4.44$ & $4.98 \pm 0.99$ & $14.86 \pm 2.11$ & $107.17 \pm 8.92$ \\
\hline & 10 & $38.07 \pm 5.52 *$ & $12.40 \pm 3.68^{*}$ & $11.53 \pm 3.09$ & $83.33 \pm 6.01^{*}$ \\
\hline SAR502250 & 0 & $16.42 \pm 2.66$ & $1.96 \pm 0.28$ & $12.68 \pm 1.29$ & $114.44 \pm 4.49$ \\
\hline \multirow{2}{*}{ (p.o.) } & 10 & $26.21 \pm 4.47 *$ & $4.50 \pm 1.22$ & $11.09 \pm 2.01$ & $101.75 \pm 5.17$ \\
\hline & 30 & $29.42 \pm 3.25^{* *}$ & $6.10 \pm 1.12^{*}$ & $11.55 \pm 1.40$ & $96.75 \pm 4.28$ \\
\hline
\end{tabular}

Table 1. Effects of fluoxetine and SAR502250 on the percentage of responses emitted in the IRT bins (49-96s) and $(0-12 \mathrm{~s})$, on the percentage of reinforced lever presses, and on the total number of lever presses in the differential reinforcement of low rate-72s (DRL-72s) procedure in rats. Fluoxetine or the appropriate vehicle was administered $30 \mathrm{~min}$ pre-session, and SAR502250 was administered $60 \mathrm{~min}$ pre-session. $* \mathrm{P}<0.05$, $* * \mathrm{P}<0.01$ vs vehicle-treated group (0): post hoc tests with a Dunn's correction, following a significant Friedman analysis. $\mathrm{N}=8$ rats per drug treatment.

restored this preferential investigation [ $10 \mathrm{mg} / \mathrm{kg}: 9.1 \mathrm{vs} 6.7 \mathrm{~s}, \mathrm{RI}=58.29 ; 30 \mathrm{mg} / \mathrm{kg}: 9.6 \mathrm{vs} 5.9 \mathrm{~s}, \mathrm{RI}=63.82$ ] (Fig. 4B).

Characterization of SAR502250 in tests predictive of therapeutic activity against psychiatric symptoms. Depression. Effects of SAR502250 in the differential reinforcement of low rate-72s (DRL-72s) procedure in rats: The prototypical antidepressant, fluoxetine at $10 \mathrm{mg} / \mathrm{kg}$, increased significantly (Friedman's $\mathrm{H}(3)=11, \mathrm{P}=0.012)$ percentage of lever-presses in the $49-96 \mathrm{~s}$ IRT, leading to a significant $[\mathrm{H}(3)=8.60$, $\mathrm{P}=0.036$ ] augmentation of the percentage of reinforced responses. The drug did not modify the percentage of 'burst responses' [i.e. percentage of responses in the IRT bin $(0-12 \mathrm{~s})][\mathrm{H}(3)=4, \mathrm{P}=0.26]$. Moreover, the antidepressant significantly $[\mathrm{H}(3)=13.20, \mathrm{P}=0.004]$ reduced the total number of responses (Table 1 ). Similarly, SAR502250 (10 mg/kg, i.p.), significantly $[\mathrm{H}(2)=9.75, \mathrm{P}=0.008]$ increased the percentage of lever-presses in the IRT bin (49-96 s), with a significant $[\mathrm{H}(2)=6.25, \mathrm{P}=0.04]$ augmentation of the percentage of reinforced responses. SAR502250 did not affect significantly the percentage of 'burst responses' $[\mathrm{H}(2)=0.75, \mathrm{P}=0.69$ ] or the total number of responses $[\mathrm{H}(2)=5.25, \mathrm{P}=0.07]$ (Table 1 ).

Effects of SAR502250 in the chronic mild stress (CMS) test in mice: Results indicated a significant stress-induced degradation in the physical state of the coat from week 2 to week 7 (Wilcoxon: at least $\mathrm{P}<0.05$ for each week) (Fig. 5). This effect was improved by SAR502250 at $30 \mathrm{mg} / \mathrm{kg}$ from week 5, by fluoxetine at $10 \mathrm{mg} / \mathrm{kg}$ from week 4 and by lithium from week 5 . All these effects lasted until the end of CMS (Fig. 5).

Anxiety. Effects of SAR502250 in the mouse defense test battery (MTDB): Before mice were exposed to the threat stimulus, neither SAR502250 [ANOVA: $\mathrm{F}(3,36)=3.77, \mathrm{P}=0.02$; post-hoc analysis vs. control: $\mathrm{P}>0.05$ ] nor diazepam (Student: $\mathrm{t}=1.07, \mathrm{P}=0.30$ ) significantly modified line crossings. In the avoidance phase, 


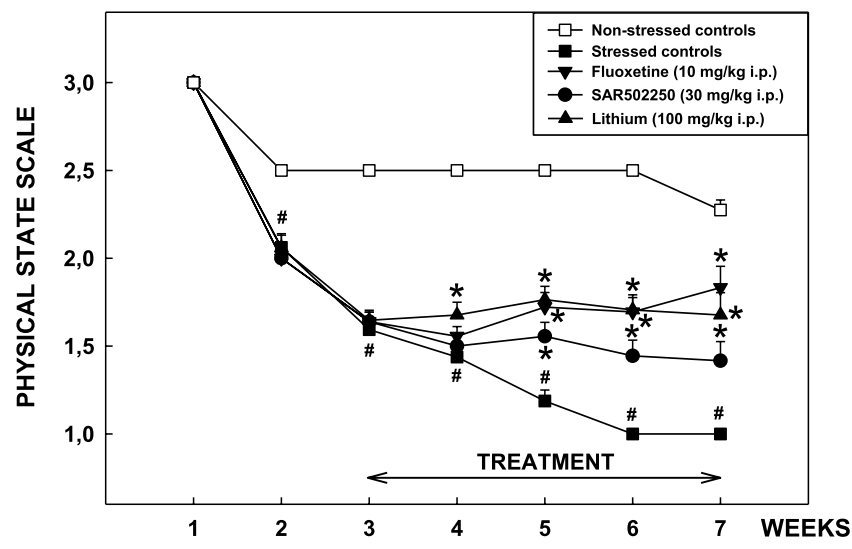

Figure 5. Effect of SAR502250, fluoxetine and lithium in the chronic mild stress procedure in mice. The vehicle or the drugs were given once-a-day 15 days after the beginning of the stress exposure and lasted until the CMS was completed. Data are expressed as mean physical state score $+\mathrm{SEM}$. $\# \mathrm{P}<0.01$ (Wilcoxon test versus nonstressed control group), $* \mathrm{P}<0.05$, $* * \mathrm{P}<0.001$ (Kruskal-Wallis one sided upper multiple comparison tests with Bonferroni-Holm correction versus stressed control group). $\mathrm{N}=20$ mice per group.

diazepam (Wilcoxon: $\mathrm{S}=46, \mathrm{P}=0.002)$, but not SAR502250 $\left(\chi^{2}=5.36, \mathrm{P}=0.15\right)$ significantly decreased avoidance frequency. When mice were chased by the threat stimulus, diazepam $(S=36, P=0.0002)$, but not $\mathrm{SAR} 502250[\mathrm{~F}(3,36)=0.08, \mathrm{P}=0.97]$ reduced significantly stops. Upon forced contact with the threat stimulus, SAR502250 significantly reduced the frequency of bites $\left(\chi^{2}=9.91, P=0.0 .02\right)$ at $30 \mathrm{mg} / \mathrm{kg}$, and diazepam at $3 \mathrm{mg} /$ $\mathrm{kg}(\mathrm{S}=36, \mathrm{P}=0.0002)$. The data are shown in Fig. 6 .

Agitation. Effects of SAR502250 on hyperactivity induced by amphetamine in mice or by PCP in PCP-sensitized rat: Results indicated that animals treated with amphetamine displayed a significant increase in locomotor activity compared to rats that received vehicle [ANOVA: $\mathrm{F}(6,64)=17.51, \mathrm{P}<0.0001$ ]. This effect was prevented by SAR502250 at all doses $(10,30$ and $60 \mathrm{mg} / \mathrm{kg})$. SAR502250 alone at the highest dose or in combination with amphetamine at 30 and $60 \mathrm{mg} / \mathrm{kg}$ significantly reduced activity compared to rats treated with vehicle (Fig. 7).

In the PCP experiment, the psychotomimetic produced a $159 \%$ increase in the number of infrared beams interruptions in control rats $(\mathrm{t}=2.66, \mathrm{P}=0.03)$. This increase was more than doubled $(+136 \%)$ in PCP-treated rats $(\mathrm{t}=8.44, \mathrm{P}<0.0001)$, indicating an hypersensitivity to the locomotor-stimulating effects of acute PCP. SAR502250 dose-dependently attenuated the hypersensitivity, producing an almost complete antagonism at $30 \mathrm{mg} / \mathrm{kg}$. This effect is displayed in Fig. 8, showing the dose-dependent attenuation of SAR502250 on the differential sensitivity to PCP between PCP-sensitized and control rats. The attenuating effect of SAR502250 reaching statistical significance $\left(\chi^{2}=9.12, P=0.058\right)$ with a significant effect of SAR502250 at $30 \mathrm{mg} / \mathrm{kg}(P=0.02)$. The doses of SAR502250 preventing hypersensitivity to PCP in PCP-treated rats, had no effect when given alone on spontaneous motor activity (recorded during the thirty minutes prior to the administration of PCP $\left(\chi^{2}=1.26, P=0.87\right)$. This suggests a selective action of SAR502250 against PCP-induced hypersensitivity, and not a non-specific locomotor effect. Finally, basal activity (recorded during the habituation period) for vehicle and PCP groups did not differ statistically $[\mathrm{F}(4,42)=1.02, \mathrm{P}=0.41]$.

Sensory gating deficit. Prepulse inhibition (PPI) deficit in Wistar rats: Wistar rats were shown to have PPI baseline level, ranging in control animals between $3.85 \pm 3.78 \%$ and $23.90 \pm 3.96 \%$ depending of the intensity of the acoustic prepulse that was applied (Fig. 9). Kruskal-Wallis analyzes indicated a significant effect of treatment on spontaneous PPI in Wistar rats at $79\left(\chi^{2}=25.72, \mathrm{P}<0.0001\right)$ and $85\left(\chi^{2}=23.86, \mathrm{P}<0.0001\right)$, but not at $72 \mathrm{~dB}\left(\chi^{2}=7.04\right.$, $\mathrm{P}=0.13)$. SAR502250 $(30 \mathrm{mg} / \mathrm{kg})$ enhanced PPI at the intensity of $85 \mathrm{~dB}$, but the effect failed to reach statistical significance $(\mathrm{P}=0.10)$. This was in contrast to clozapine, which significantly potentiated PPI at 79 and $85 \mathrm{~dB}$ (both $\mathrm{P}<0.001$ ). Basal startle amplitude was not significantly altered by SAR502250 or clozapine (data not shown).

\section{Discussion}

This work had two main goals. The first was to evaluate the neuroprotective potential of the GSK3 inhibitor, SAR502250. The second objective was to verify whether the drug is able to attenuate behavioral alterations reminiscent of NPS associated with AD. Results demonstrated that the drug reduced tau hyperphosphorylation, neuronal cell death and ameliorated some NPS.

Characterization of SAR502250 in tests relevant to assess therapeutic activity against AD. There is evidence indicating that GSK3 is closely involved in tau hyperphosphorylation, the increased production of $\mathrm{A} \beta$ in $\mathrm{AD}$ pathology and in memory impairment ${ }^{7,40}$. The kinase induces hyperphosphorylation of tau at several primed (e.g., Tyr231) and non-primed (e.g., $S_{396}$ ) phosphorylation sites in cellular neurodegeneration assays, indicating that GSK3 is a key tau kinase in the formation of neurofibrillary tangles (NFT) and ultimately neuronal death ${ }^{8}$. Consistent with these findings, conditional transgenic mice overexpressing GSK3 display tau hyperphosphorylation and neurodegeneration ${ }^{41}$, while pharmacological inhibition of the kinase prevents tau 
A

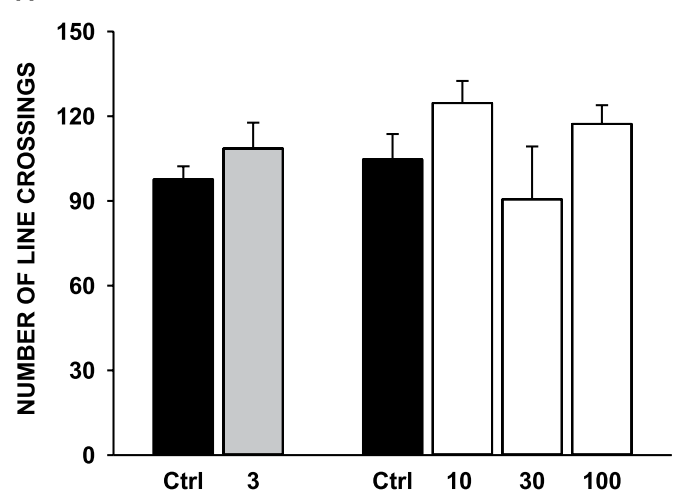

C

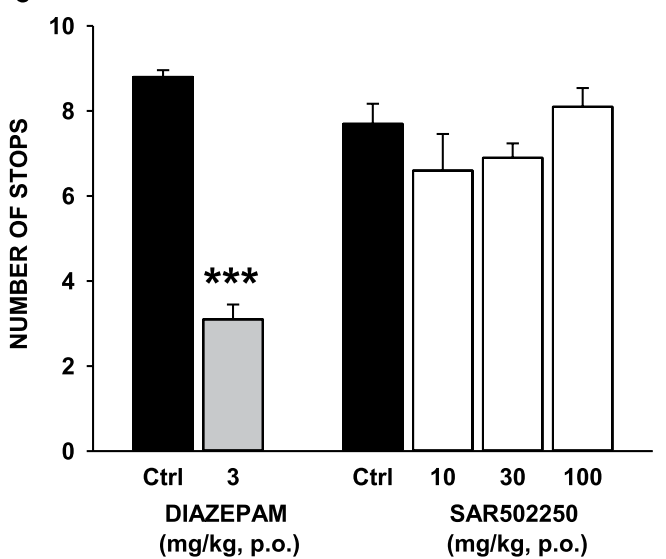

B

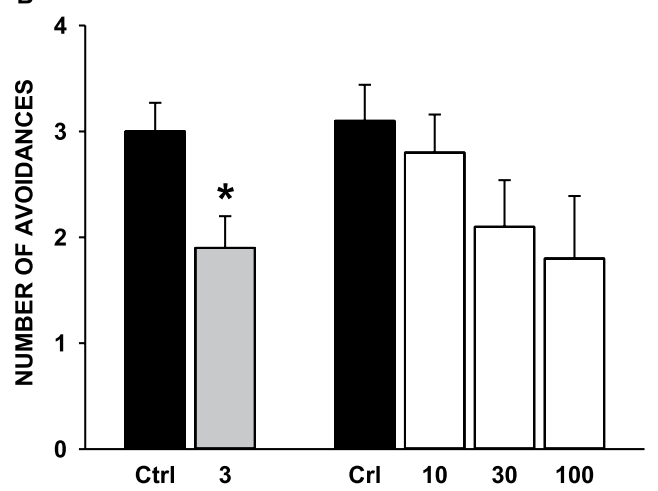

D

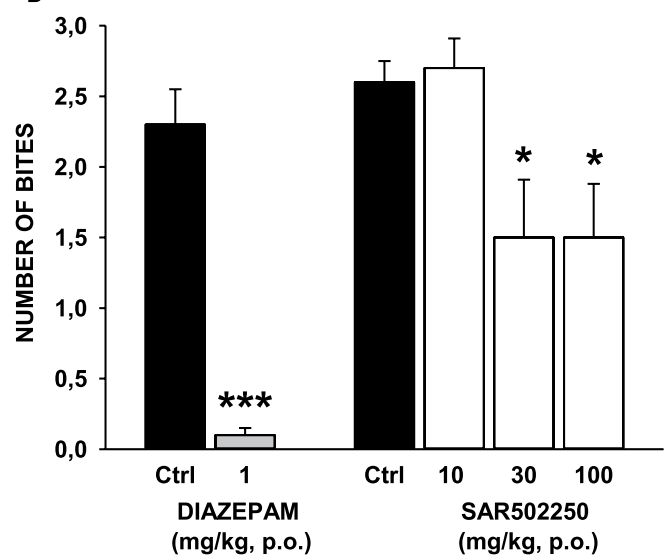

Figure 6. Effects of SAR502250 and diazepam in the mouse defense test battery on (A), locomotor activity prior to the exposure to the threat; (B), flight response in response to the approaching rat; (C), risk assessment when the rat was chasing the mouse, and (D), defensive attack reactions upon forced contact with the rat. The vehicle or the drugs were administered 60 minutes prior to testing. Data represent mean $+\mathrm{SEM}, * \mathrm{P}<0.05$ and $* * * \mathrm{P}<0.001 . \mathrm{N}=8-11$ mice per group.

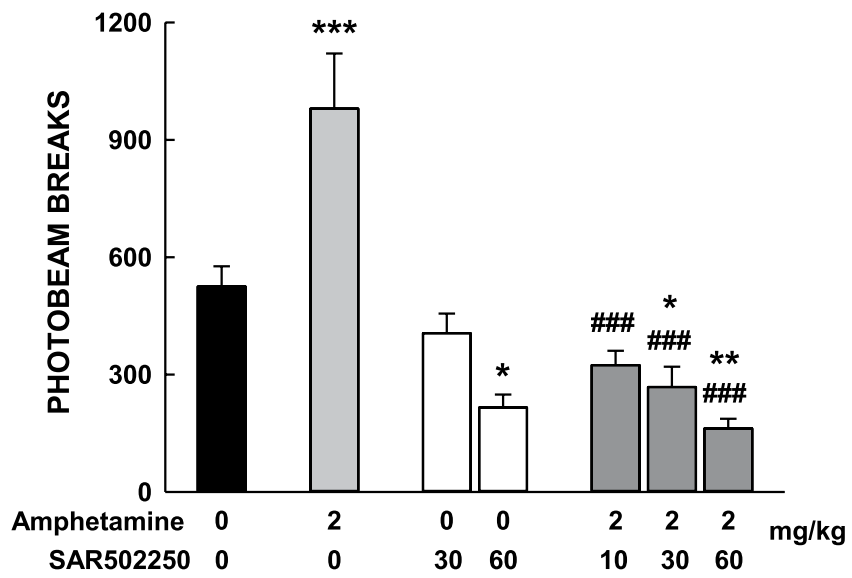

Figure 7. Effects of SAR502250 on motor hyperactivity induced by amphetamine in mice. Animals were pretreated with SAR502250 or vehicle, followed $30 \mathrm{~min}$ later by a challenge administration of vehicle or amphetamine. Immediately thereafter, they were placed in the activity cages devices. Data represent mean + SEM, $* \mathrm{P}<0.05, * * \mathrm{P}<0.01$ and $* * * \mathrm{P}<0.001$ (vs vehicle control); ${ }^{\# \#} \mathrm{P}<0.001$ (vs amphetamine, Newman-Keuls). $\mathrm{N}=10-11$ mice per group.

hyperphosphorylation in normal mice or in a transgenic model of $\mathrm{AD}^{28,29,42-45}$. In line with these findings are the present data with SAR502250 demonstrating that oral administration of the drug decreased hyperphosphorylation on $\mathrm{S}_{396}$ in the spinal cord and cortex in P301L human tau transgenic mice. 


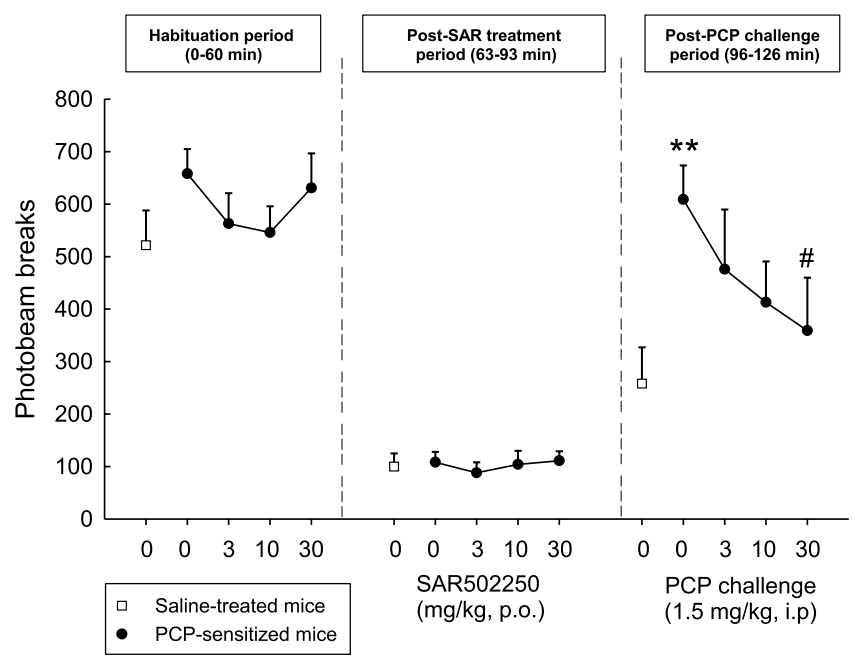

Figure 8. Antagonism by SAR502250 of the hypersensitivity to an acute challenge with PCP in rats sensitized to PCP. Data represent mean + SEM number of infrared beam interruptions recorded for 90 min, immediately after an injection of PCP (1.5 mg/kg i.p.) or vehicle, which was preceded 30 min earlier by an p.o. injection of SAR502250 or vehicle. ${ }^{* * P}<0.01$, PCP-sensitized rats compared to vehicle-treated rat. ${ }^{*} \mathrm{P}<0.05$ compared to acute $\mathrm{PCP} / \mathrm{PCP}$-sensitized rats. $\mathrm{N}=9-10$ rats per group.

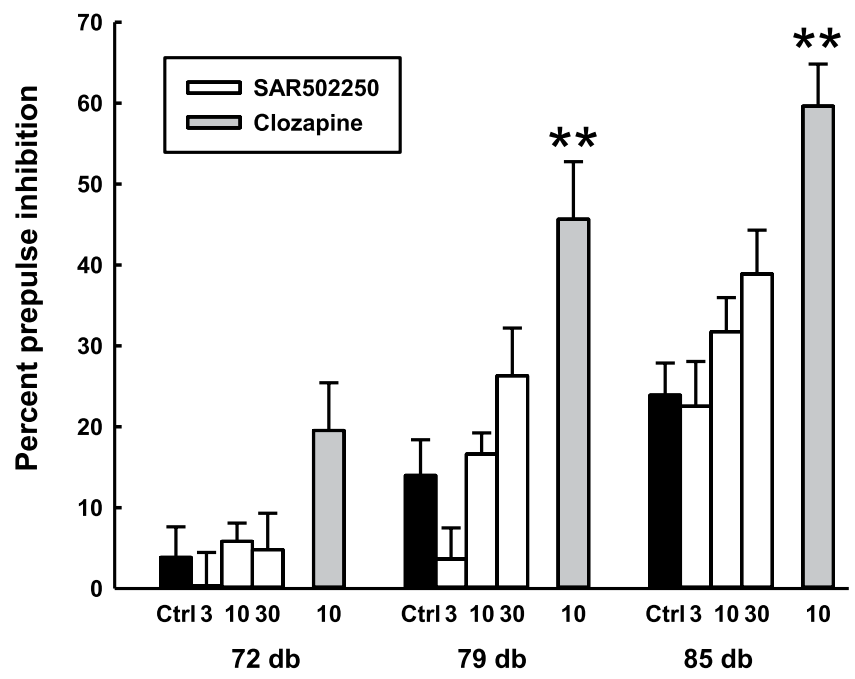

Figure 9. Reversion by SAR502250 and clozapine of a spontaneous deficit of prepulse inhibition of the startle reflex in Wistar rats. Prepulse inhibition expressed as a function of prepulse (PP) intensity (in dB). The vehicle or the drugs were administered 60 minutes prior to testing. Each bar represents the mean $+\mathrm{SEM}$. $* \mathrm{P}<0.05$, $* * \mathrm{P}<0.01$ vs vehicle (Kruskal-Wallis or Wilcoxon test at the corresponding prepulse intensity. $\mathrm{N}=16-19$ rats per group.

There is accumulating evidence that GSK3 plays a role in the function of $A \beta$, which is further upstream of tau in the pathological progression of $\mathrm{AD}^{46}$. Exposure of neuronal cells to toxic $\mathrm{A} \beta$ increases the activity of GSK3, which in turn facilitates the processing of amyloid precursor protein (APP) leading to an upregulation of A $\beta$ synthesis and aggregation via the phosphorylation of tau. Genetic or pharmacological deactivation of GSK3 was reported to decrease toxicity associated with $A \beta$, ameliorate $A \beta$-induced behavioral impairments, and rescue the loss of neurons in APP-overexpressing mice ${ }^{11,47-53}$. The results of our study are in line with these observations. They showed that SAR502250 prevented the increase in cell death in rat embryonic hippocampal neurons following application of the neurotoxic fragment of the full-length $A \beta$ peptide, $A \beta_{25-35}$. The intra ventricle injection of the $A \beta_{25-35}$ peptide was demonstrated to produce neurotoxic effects similar to those produced by the $A \beta_{1-40}$ peptide $^{54,55}$, including cellular and cerebral oxidative stress, and neuroinflammation, modified endogenous amyloid processing, provoking hippocampal morphological alterations and a rapid glial activation ${ }^{56}$. Moreover, studies demonstrated impairment in memory processes when the amyloid fragment was infused into the ventricle or locally applied into the hippocampus of rodents ${ }^{56-62}$. In this study, infusion of the $\beta_{25-35}$ fragment in cerebral ventricles of mice produced a deficit in short-term episodic memory in the object recognition test. This effect 
can be attributed to $A \beta_{25-35}$, since the scrambled $A \beta_{25-35}$ peptide had no such an action. The administration of SAR502250 prior to the acquisition session attenuated this deficit. The procognitive effects of SAR502250 were demonstrated further in transgenic APP(SW)/Tau(VLW) mice, described to display many pathological features, reminiscent of those observed in $\mathrm{AD}$, including severe learning deficit ${ }^{63,64}$. Here, they displayed impaired memory performance in the object recognition task, which were completely rescued by SAR502250 following a 7-week treatment. The memory-improving effects of SAR502250 agree with previous studies showing that other GSK3 inhibitors enhance cognitive functions in animal models ${ }^{65-68}$. The ability of GSK3 inhibitors to improve memory performance has been suggested to involve various mechanisms, including modification in synaptic plasticity (i.e. facilitation of long-term potentiation (LTP) induction and long-term depression diminution) and promoting adult hippocampal neurogenesis ${ }^{69}$. Altogether, the current findings with SAR502250 in experimental models of $\mathrm{AD}$ support further the idea that GSK3 inhibition represents a potential disease-modifying approach for the treatment of this condition. Although several GSK3 inhibitors have been in the pipeline for the treatment of AD, proof of efficacy has not been established yet. A double-blind, placebo controlled, Phase 2 study with the GSK3 inhibitor tideglusib in mild to moderate $\mathrm{AD}$ patients did not show clinical efficacy, although mild $\mathrm{AD}$ participants in the lowest dose group showed significant responses on the primary and several secondary measures of efficacy, suggesting that disease stage and GSK3 inhibition level are critical parameters in clinical studies with GSK3 inhibitors in $\mathrm{AD}$ patients ${ }^{70}$.

Characterization of SAR502250 in tests of psychiatric symptoms. It is widely acknowledged that $\mathrm{AD}$ presents with a complex clinical phenotype including several psychiatric symptoms, some of which predict disease prognosis. Unfortunately, their clinical management remains challenging because AD patients respond poorly to existing medications. Depression is among the most prevalent psychiatric symptom in AD affecting $42 \%$ of patients based on a recent meta-analysis ${ }^{2}$. GSK3 inhibitors have been demonstrated to produce antidepressant-like effects. Kaidanovich-Beilin and colleagues were the first to demonstrate that L803-mts, a peptide inhibitor of GSK3, produces antidepressant-like effects in the forced-swimming test following intracerebral ventricle injections in mice ${ }^{24}$. Follow-up studies using the same behavioral assay extended these findings, showing antidepressant-like effects after systemic administration of other GSK3 inhibitors, such as AR-A014418 $8^{25,71}$ and NP031115 ${ }^{26}$. More recently, repeated administration of the GSK3 inhibitor VP2.51 was found to produce antidepressant-like effects in the forced-swimming test in non-stressed mice as well as in previously stressed animals ${ }^{27}$. While the forced-swimming test is a commonly used assay, it has limited validity as a model of depres$\operatorname{sion}^{72}$. Here, we used the CMS and DRL-72 s schedule procedures, two models claimed to have good face and predictive validity ${ }^{73,74}$. In the DRL-72 s procedure, SAR502250 displayed antidepressant-like activity, increasing the percentage of responses in the inter-response time (IRT) bin (49-96s), resulting in a higher number of reinforced presses. These effects resemble that elicited in the current study by fluoxetine, a conventional antidepressant, which was used as positive control. However, the magnitude of the effect was less with the GSK3 inhibitor. The antidepressant-like potential of SAR502250 was demonstrated further using the CMS test after chronic administration of the drug for 28 days. SAR502250 ameliorated chronic stress-induced degradation of the physical state of the coat, suggesting that the drug normalized grooming, which was impaired by repeated stress. Again, this effect was less pronounced when compared to the antidepressant, fluoxetine. The precise mechanism(s) by which inhibition of GSK3 results in antidepressant-like activity remain(s) to be delineated. It has been proposed recently that GSK3 inhibitors produce their antidepressant-like action by promoting hippocampal neurogenesis, increasing cell proliferation and survival of newborn neurons ${ }^{27}$. Interestingly, this study further showed that pharmacological blockade of neurogenesis impaired the ability of the GSK3 inhibitor to produce antidepressant-like action, indicating that these effects are neurogenesis-dependent.

Little is known on potential effects of GSK inhibition on the modulation of anxiety and aggression, two frequent comorbid symptoms of $\mathrm{AD}$, whose prevalence is estimated around $40 \%^{2}$. One study reported that genetic or pharmacological blockade in the activity of GSK3 reduced anxiety-like behaviors in knock-in mice bearing a mutant form of tryptophan hydroxylase 2 (Tph2), the brain 5 -HT synthesis enzyme ${ }^{13}$. However, a similar activity was not observed in normal mice following the administration of the selective GSK3 inhibitor, VP2.5127. Here we used the mouse defense test battery (MDTB) to investigate potential effects of SAR502250 on emotional behavior. The behaviors displayed by mice in this test have been shown to relate to different aspects of anxiety and defensive aggression, which relate either to affective-orientated defense reactions or to the process of acquiring and analyzing information in the presence of threatening stimuli ${ }^{75}$. Our findings show that SAR502250 weakly modified risk assessment and flight, behaviors that have been demonstrated to be more sensitive to selective 5-HT reuptake inhibitors or to benzodiazepines, i.e., drugs generally used to treat panic and generalized anxiety disorders. However, it decreased significantly defensive aggression, a terminal defense reaction, suggesting that SAR502250 may be useful to attenuate certain forms of aggressive behaviors. The mechanisms underlying the specificity by which SAR502250 exerts anti-aggressive effects remain to be fully elucidated. Findings with Tph2 knock-in mice, which show a dramatic decrease in central 5-HT function may, however, be relevant to his issue. These mice display enhanced aggressive behavior, a phenomenon which is not observed in animals that were additionally haplo-insufficient for GSK3, indicating that reduced GSK3 expression rescued abnormal aggression in Tph $2^{13}$. While it is tempting to speculate that the 5-HT system plays a role in the anti-aggressive effects of SAR502250 in the MDTB, the current study does not provide any evidence supporting this idea. Clearly, more studies are needed to determine more precisely the mechanisms underlying the anti-aggressive effects of SAR502250.

Hyperactivity, including agitation and excessive motor activity, is a frequently occurring sub-syndrome in $\mathrm{AD}^{2}$. It is severe enough to produce disability, worsens as disease severity increases, and is predictive of more rapid decline ${ }^{1}$. Several medications, including antipsychotics, anxiolytics or antidepressants, have been used to treat this syndrome, but have shown limited efficacy ${ }^{1}$. Nevertheless, a recent open label case series in patients with $\mathrm{AD}$ showed that a low dose of lithium may represent an effective treatment of agitation ${ }^{76}$, suggesting that GSK3 
inhibitors may be useful in the management of this symptom in $\mathrm{AD}$ patients. In preclinical studies, transgenic mice overexpressing GSK3 have been shown to display enhanced locomotor activity compared to their wild-type counterparts $^{77}$. Moreover, selective GSK3 inhibitors were found to decrease hyperactivity and expression of behavioral sensitization in the mouse following the administration of psychostimulant drugs, such as amphetamine or cocaine ${ }^{78-81}$. In the present study, SAR502250 attenuated hyperactivity induced by amphetamine in naïve mice or following an injection of PCP in PCP-sensitized rats. Psychostimulant-induced hyperactivity has been associated with an enhanced dopaminergic transmission within the nigrostriatal and mesolimbic dopamine pathways $^{82-85}$. Results from an earlier study showed that the ability of the non-selective GSK3 inhibitor, valproic acid, to inhibit hyperactivity induced by amphetamine is associated with its ability to modulate the activity of GSK3 in the frontal cortex and caudate putamen, which receive dopaminergic projections from the substantia nigra and nucleus accumbens, respectively. Moreover, valproic acid increased phosphorylation of $S_{9}-G S K 3$ in the caudate putamen, and $S_{21}$ and $S_{9}$ in the frontal cortex, suggesting an inhibitory action of the kinase in these regions ${ }^{81}$. Although these findings highlight the importance of GSK3 in mediating hyperactivity elicited by enhanced dopaminergic transmission, it is unclear whether the same mechanism is involved in hyperactivity in AD patients and the efficacy of lithium in alleviating this symptom.

Deficit in sensorimotor gating is another symptom that has been shown in AD patients ${ }^{86-90}$. Sensorimotor gating is described as a putative neural mechanism that inhibits the processing of extraneous cognitive, sensory and motor information, allowing mental and behavioral integration ${ }^{91}$. In preclinical studies, this phenomenon is classically evaluated by the prepulse inhibition (PPI) of the startle response. APP/PS1 transgenic mice, which are widely used as a model of AD, display impaired PPI, a deficit associated with A $\beta$ neuropathology and memory impairment ${ }^{92}$. Here, we used Wistar rats, a strain which shows a near total lack of PPI, to model sensory gating deficit ${ }^{93}$. Results showed that SAR502250 failed to significantly attenuate the deficit in PPI in Wistar rats. Although evidence suggests that GSK3 is involved in sensorimotor gating ${ }^{20,21,23,94}$, studies that investigated the effects of genetic and/or pharmacological blockade of GSK3 on PPI have yielded inconsistent results. Several authors reported that GSK3 inhibitors rescued the deficit in PPI in mutant mice displaying a schizophrenia- or compulsive-relevant behavioral phenotype ${ }^{95-97}$. However, contradictory evidence has also been reported. Indeed, findings from experiments using genetic or pharmacological manipulations that reduce GSK3 function have shown an attenuation in PPI in C57BL/6J mice, suggesting that GSK3 facilitates sensorimotor gating ${ }^{98}$. The reasons for this apparent discrepancy in the modulation of PPI following GSK3 inhibition remain to be determined. Perhaps it could reflect differences in the degree to which GSK3 function is altered in these models. Thus, the transgenic mice expressing a disease mutation used in the aforementioned studies ${ }^{95,96}$ display altered GSK3 signaling and impaired interplay with key proteins involved in development, such as DISC1 and AKT1, a feature not seen in wild-type strains such as the Wistar line used in the current study. However, more studies are necessary in order to establish the generality of this assumption.

Taken together, the present findings with SAR502250 on behaviors reminiscent of NPS in AD suggest that GSK3 inhibitors may be useful in treating these comorbid symptoms. However, it is important to emphasize that - with the exception of the cognitive tasks - our results were obtained in non-pathological models of AD. It cannot be excluded that the behavioral profiles displayed by wild-type strains following SAR502250 administration may have been different in transgenic or pharmacological models of AD. Clearly, further experiments using procedures that are more suitable than the current ones to be used with animal models of AD are warranted to determine more precisely the potential of GSK3 inhibitors in managing NPS in AD.

\section{Conclusion}

Our study demonstrates that the selective inhibitor of GSK3, SAR502250 displays efficacy on biochemical and behavioral markers of $\mathrm{AD}$, thus confirming the therapeutic potential of GSK3 inhibitors against this condition. Moreover, the current work provides evidence that blockade of this kinase interferes with behaviors impaired in $\mathrm{AD}$, suggesting that GSK3 inhibitors may have both disease-modifying and symptomatic potential in the treatment of AD.

\section{Data availability}

The datasets generated during and/or analyzed during the current study are available from the corresponding author on reasonable request.

Received: 14 June 2019; Accepted: 15 November 2019;

Published online: 02 December 2019

\section{References}

1. Lanctot, K. L. et al. Neuropsychiatric signs and symptoms of Alzheimer's disease: New treatment paradigms. Alzheimers Dement (N Y) 3, 440-449, https://doi.org/10.1016/j.trci.2017.07.001 (2017).

2. Zhao, Q. F. et al. The prevalence of neuropsychiatric symptoms in Alzheimer's disease: Systematic review and meta-analysis. J Affect Disord 190, 264-271, https://doi.org/10.1016/j.jad.2015.09.069 (2016).

3. Rabins, P. V. et al. Predictors of progression to severe Alzheimer's disease in an incidence sample. Alzheimers Dement 9, 204-207, https://doi.org/10.1016/j.jalz.2012.01.003 (2013).

4. Martinez, A. Preclinical efficacy on GSK-3 inhibitors: towards a future generation of powerful drugs. Med Res Rev 28, 773-796, https://doi.org/10.1002/med.20119 (2008).

5. Frame, S. \& Cohen, P. GSK3 takes centre stage more than 20 years after its discovery. Biochem J 359, 1-16 (2001).

6. Frame, S., Cohen, P. \& Biondi, R. M. A common phosphate binding site explains the unique substrate specificity of GSK3 and its inactivation by phosphorylation. Mol Cell 7, 1321-1327 (2001).

7. Hooper, C., Killick, R. \& Lovestone, S. The GSK3 hypothesis of Alzheimer's disease. J Neurochem 104, 1433-1439, https://doi. org/10.1111/j.1471-4159.2007.05194.x (2008). 
8. Maqbool, M., Mobashir, M. \& Hoda, N. Pivotal role of glycogen synthase kinase-3: A therapeutic target for Alzheimer's disease. Eur J Med Chem 107, 63-81, https://doi.org/10.1016/j.ejmech.2015.10.018 (2016).

9. Saraswati, A. P., Ali Hussaini, S. M., Krishna, N. H., Babu, B. N. \& Kamal, A. Glycogen synthase kinase-3 and its inhibitors: Potential target for various therapeutic conditions. Eur J Med Chem 144, 843-858, https://doi.org/10.1016/j.ejmech.2017.11.103 (2018).

10. Medina, M. \& Castro, A. Glycogen synthase kinase-3 (GSK-3) inhibitors reach the clinic. Curr Opin Drug Discov Devel 11, 533-543 (2008).

11. Phiel, C. J., Wilson, C. A., Lee, V. M. \& Klein, P. S. GSK-3alpha regulates production of Alzheimer's disease amyloid-beta peptides. Nature 423, 435-439, https://doi.org/10.1038/nature01640 (2003).

12. Su, Y. et al. Lithium, a common drug for bipolar disorder treatment, regulates amyloid-beta precursor protein processing. Biochemistry 43, 6899-6908, https://doi.org/10.1021/bi035627j (2004).

13. Beaulieu, J. M. et al. Role of GSK3 beta in behavioral abnormalities induced by serotonin deficiency. Proc Natl Acad Sci USA 105, 1333-1338, https://doi.org/10.1073/pnas.0711496105 (2008).

14. Zunszain, P. A., Horowitz, M. A., Cattaneo, A., Lupi, M. M. \& Pariante, C. M. Ketamine: synaptogenesis, immunomodulation and glycogen synthase kinase-3 as underlying mechanisms of its antidepressant properties. Mol Psychiatry 18, 1236-1241, https://doi. org/10.1038/mp.2013.87 (2013)

15. Hui, J. et al. Fluoxetine regulates neurogenesis in vitro through modulation of GSK-3beta/beta-catenin signaling. Int $J$ Neuropsychopharmacol 18, https://doi.org/10.1093/ijnp/pyu099 (2014).

16. Liu, R. J. et al. GSK-3 inhibition potentiates the synaptogenic and antidepressant-like effects of subthreshold doses of ketamine. Neuropsychopharmacology 38, 2268-2277, https://doi.org/10.1038/npp.2013.128 (2013).

17. Wu, C. et al. Escitalopram alleviates stress-induced Alzheimer's disease-like tau pathologies and cognitive deficits by reducing hypothalamic-pituitary-adrenal axis reactivity and insulin/GSK-3beta signal pathway activity. Neurobiol Aging 67, 137-147, https:// doi.org/10.1016/j.neurobiolaging.2018.03.011 (2018).

18. Emamian, E. S., Hall, D., Birnbaum, M. J., Karayiorgou, M. \& Gogos, J. A. Convergent evidence for impaired AKT1-GSK3beta signaling in schizophrenia. Nat Genet 36, 131-137, https://doi.org/10.1038/ng1296 (2004).

19. Koros, E. \& Dorner-Ciossek, C. The role of glycogen synthase kinase-3beta in schizophrenia. Drug News Perspect 20, 437-445, https://doi.org/10.1358/dnp.2007.20.7.1149632 (2007)

20. Alimohamad, H., Rajakumar, N., Seah, Y. H. \& Rushlow, W. Antipsychotics alter the protein expression levels of beta-catenin and GSK-3 in the rat medial prefrontal cortex and striatum. Biol Psychiatry 57, 533-542, https://doi.org/10.1016/j.biopsych.2004.11.036 (2005).

21. Alimohamad, H., Sutton, L., Mouyal, J., Rajakumar, N. \& Rushlow, W. J. The effects of antipsychotics on beta-catenin, glycogen synthase kinase-3 and dishevelled in the ventral midbrain of rats. J Neurochem 95, 513-525, https://doi. org/10.1111/j.1471-4159.2005.03388.x (2005)

22. Kozlovsky, N., Amar, S., Belmaker, R. H. \& Agam, G. Psychotropic drugs affect Ser9-phosphorylated GSK-3 beta protein levels in rodent frontal cortex. Int J Neuropsychopharmacol 9, 337-342, https://doi.org/10.1017/S1461145705006097 (2006).

23. Li, X., Rosborough, K. M., Friedman, A. B., Zhu, W. \& Roth, K. A. Regulation of mouse brain glycogen synthase kinase-3 by atypical antipsychotics. Int J Neuropsychopharmacol 10, 7-19, https://doi.org/10.1017/S1461145706006547 (2007).

24. Kaidanovich-Beilin, O., Milman, A., Weizman, A., Pick, C. G. \& Eldar-Finkelman, H. Rapid antidepressive-like activity of specific glycogen synthase kinase-3 inhibitor and its effect on beta-catenin in mouse hippocampus. Biol Psychiatry 55, 781-784, https://doi. org/10.1016/j.biopsych.2004.01.008 (2004).

25. Gould, T. D., Einat, H., Bhat, R. \& Manji, H. K. AR-A014418, a selective GSK-3 inhibitor, produces antidepressant-like effects in the forced swim test. Int J Neuropsychopharmacol 7, 387-390, https://doi.org/10.1017/S1461145704004535 (2004).

26. Rosa, A. O. et al. Antidepressant-like effect of the novel thiadiazolidinone NP031115 in mice. Prog Neuropsychopharmacol Biol Psychiatry 32, 1549-1556, https://doi.org/10.1016/j.pnpbp.2008.05.020 (2008).

27. Perez-Domper, P. et al. The GSK-3-inhibitor VP2.51 produces antidepressant effects associated with adult hippocampal neurogenesis. Neuropharmacology 116, 174-187, https://doi.org/10.1016/j.neuropharm.2016.12.019 (2017).

28. Uehara, F. et al. 6-(4-Pyridyl)pyrimidin-4(3H)-ones as CNS penetrant glycogen synthase kinase-3beta inhibitors. Bioorg Med Chem Lett 23, 6928-6932, https://doi.org/10.1016/j.bmcl.2013.09.021 (2013).

29. Fukunaga, K. et al. 2-(2-Phenylmorpholin-4-yl)pyrimidin-4(3H)-ones; a new class of potent, selective and orally active glycogen synthase kinase-3beta inhibitors. Bioorg Med Chem Lett 23, 6933-6937, https://doi.org/10.1016/j.bmcl.2013.09.020 (2013).

30. Griebel, G. et al. SAR110894, a potent histamine H(3)-receptor antagonist, displays procognitive effects in rodents. Pharmacol Biochem Behav 102, 203-214, https://doi.org/10.1016/j.pbb.2012.04.004 (2012).

31. Ennaceur, A. \& Delacour, J. A new one-trial test for neurobiological studies of memory in rats. 1: Behavioral data. Behav. Brain Res 31, 47-59, 0166-4328(88)90157-X (1988).

32. Louis, C., Cohen, C., Depoortere, R. \& Griebel, G. Antidepressant-like effects of the corticotropin-releasing factor 1 receptor antagonist, SSR125543, and the vasopressin 1b receptor antagonist, SSR149415, in a DRL-72 s schedule in the rat. Neuropsychopharmacology 31, 2180-2187 (2006).

33. Richards, J. B., Sabol, K. E. \& Seiden, L. S. DRL interresponse-time distributions: quantification by peak deviation analysis. J Exp Anal Behav 60, 361-385, https://doi.org/10.1901/jeab.1993.60-361 (1993).

34. Cohen, C., Perrault, G. \& Sanger, D. J. Assessment of the antidepressant-like effects of L-type voltage-dependent channel modulators. Behav Pharmacol 8, 629-638 (1997).

35. Yalcin, I., Belzung, C. \& Surget, A. Mouse strain differences in the unpredictable chronic mild stress: a four-antidepressant survey. Behav Brain Res 193, 140-143, https://doi.org/10.1016/j.bbr.2008.04.021 (2008).

36. Griebel, G. et al. Anxiolytic- and antidepressant-like effects of the non-peptide vasopressin V1b receptor antagonist, SSR149415, suggest an innovative approach for the treatment of stress-related disorders. Proc Natl Acad Sci USA 99, 6370-6375, https://doi. org/10.1073/pnas.092012099 (2002).

37. Griebel, G. S. D. P. G. Genetic differences in the Mouse Defense test Battery. Aggressive Behavior 23, 19-31 (1997)

38. Griebel, G., Blanchard, D. C., Jung, A. \& Blanchard, R. J. A model of 'antipredator' defense in Swiss-Webster mice: effects of benzodiazepine receptor ligands with different intrinsic activities. Behav. Pharmacol 6, 732-745 (1995).

39. Depoortere, R., Perrault, G. \& Sanger, D. J. Some, but not all, antipsychotic drugs potentiate a low level of prepulse inhibition shown by rats of the Wistar strain. Behav Pharmacol 8, 364-372 (1997).

40. Sharma, N. et al. Loss of biliverdin reductase-A favors Tau hyper-phosphorylation in Alzheimer's disease. Neurobiol Dis 125, 176-189, https://doi.org/10.1016/j.nbd.2019.02.003 (2019).

41. Lucas, J. J. et al. Decreased nuclear beta-catenin, tau hyperphosphorylation and neurodegeneration in GSK-3beta conditional transgenic mice. $E M B O J$ 20, 27-39, https://doi.org/10.1093/emboj/20.1.27 (2001).

42. Engel, T., Hernandez, F., Avila, J. \& Lucas, J. J. Full reversal of Alzheimer's disease-like phenotype in a mouse model with conditional overexpression of glycogen synthase kinase-3. J Neurosci 26, 5083-5090, https://doi.org/10.1523/JNEUROSCI.0604-06.2006 (2006).

43. La Pietra, V. et al. Design, synthesis, and biological evaluation of 1-phenylpyrazolo[3,4-e]pyrrolo[3,4-g]indolizine-4,6(1H,5H)diones as new glycogen synthase kinase-3beta inhibitors. J Med Chem 56, 10066-10078, https://doi.org/10.1021/jm401466v (2013).

44. Fukunaga, K. et al. Discovery of novel 2-(alkylmorpholin-4-yl)-6-(3-fluoropyridin-4-yl)-pyrimidin-4(3H)-ones as orally-active GSK-3beta inhibitors for Alzheimer's disease. Bioorg Med Chem Lett 25, 1086-1091, https://doi.org/10.1016/j.bmcl.2015.01.005 (2015). 
45. Luo, G. et al. Discovery of Isonicotinamides as Highly Selective, Brain Penetrable, and Orally Active Glycogen Synthase Kinase-3 Inhibitors. J Med Chem 59, 1041-1051, https://doi.org/10.1021/acs.jmedchem.5b01550 (2016).

46. Blennow, K., de Leon, M. J. \& Zetterberg, H. Alzheimer's disease. Lancet 368, 387-403, https://doi.org/10.1016/S01406736(06)69113-7 (2006).

47. Takashima, A., Noguchi, K., Sato, K., Hoshino, T. \& Imahori, K. Tau protein kinase I is essential for amyloid beta-protein-induced neurotoxicity. Proc Natl Acad Sci USA 90, 7789-7793 (1993).

48. Takashima, A. et al. Exposure of rat hippocampal neurons to amyloid beta peptide (25-35) induces the inactivation of phosphatidyl inositol-3 kinase and the activation of tau protein kinase I/glycogen synthase kinase-3 beta. Neurosci Lett 203, 33-36 (1996).

49. Aplin, A. E., Jacobsen, J. S., Anderton, B. H. \& Gallo, J. M. Effect of increased glycogen synthase kinase-3 activity upon the maturation of the amyloid precursor protein in transfected cells. Neuroreport 8, 639-643 (1997).

50. Alvarez, A., Toro, R., Caceres, A. \& Maccioni, R. B. Inhibition of tau phosphorylating protein kinase cdk5 prevents beta-amyloidinduced neuronal death. FEBS Lett 459, 421-426 (1999).

51. Rockenstein, E. et al. Neuroprotective effects of regulators of the glycogen synthase kinase-3beta signaling pathway in a transgenic model of Alzheimer's disease are associated with reduced amyloid precursor protein phosphorylation. J Neurosci 27, 1981-1991, https://doi.org/10.1523/JNEUROSCI.4321-06.2007 (2007).

52. Brunden, K. R., Trojanowski, J. Q. \& Lee, V. M. Advances in tau-focused drug discovery for Alzheimer's disease and related tauopathies. Nat Rev Drug Discov 8, 783-793, https://doi.org/10.1038/nrd2959 (2009).

53. Lei, P., Ayton, S., Bush, A. I. \& Adlard, P. A. GSK-3 in Neurodegenerative Diseases. Int J Alzheimers Dis 2011, 189246, https://doi. org/10.4061/2011/189246 (2011).

54. Kowall, N. W. \& Beal, M. F. Glutamate-, glutaminase-, and taurine-immunoreactive neurons develop neurofibrillary tangles in Alzheimer's disease. Ann Neurol 29, 162-167, https://doi.org/10.1002/ana.410290208 (1991)

55. Yamada, K. \& Nabeshima, T. Animal models of Alzheimer's disease and evaluation of anti-dementia drugs. Pharmacol Ther 88, 93-113 (2000).

56. Zussy, C. et al. Time-course and regional analyses of the physiopathological changes induced after cerebral injection of an amyloid beta fragment in rats. Am J Pathol 179, 315-334, https://doi.org/10.1016/j.ajpath.2011.03.021 (2011).

57. Chen, S. Y., Wright, J. W. \& Barnes, C. D. The neurochemical and behavioral effects of beta-amyloid peptide(25-35). Brain Res 720 , 54-60, https://doi.org/10.1016/0006-8993(96)00136-9 (1996).

58. Dornan, W. A., Kang, D. E., McCampbell, A. \& Kang, E. E. Bilateral injections of beta A(25-35) + IBO into the hippocampus disrupts acquisition of spatial learning in the rat. Neuroreport 5, 165-168 (1993).

59. Kim, D. H. et al. Cognitive dysfunctions induced by a cholinergic blockade and Abeta 25-35 peptide are attenuated by salvianolic acid B. Neuropharmacology 61, 1432-1440, https://doi.org/10.1016/j.neuropharm.2011.08.038 (2011).

60. Maurice, T., Lockhart, B. P. \& Privat, A. Amnesia induced in mice by centrally administered beta-amyloid peptides involves cholinergic dysfunction. Brain Res 706, 181-193 (1996).

61. Olariu, A. et al. Memory deficits and increased emotionality induced by beta-amyloid (25-35) are correlated with the reduced acetylcholine release and altered phorbol dibutyrate binding in the hippocampus. J Neural Transm (Vienna) 108, 1065-1079, https:// doi.org/10.1007/s007020170025 (2001).

62. Griebel, G. et al. SAR110894, a potent histamine $\mathrm{H}_{3}$-receptor antagonist, displays procognitive effects in rodents. Pharmacol. Biochem. Behav 102, 203-214, S0091-3057(12)00114-1;10.1016/j.pbb.2012.04.004 [doi] (2012).

63. Gotz, J. et al. Transgenic animal models of Alzheimer's disease and related disorders: histopathology, behavior and therapy. Mol Psychiatry 9, 664-683, https://doi.org/10.1038/sj.mp.4001508 (2004).

64. Perez, M., Moran, M. A., Ferrer, I., Avila, J. \& Gomez-Ramos, P. Phosphorylated tau in neuritic plaques of APP(sw)/Tau (vlw) transgenic mice and Alzheimer disease. Acta Neuropathol 116, 409-418, https://doi.org/10.1007/s00401-008-0420-0 (2008)

65. Nocjar, C., Hammonds, M. D. \& Shim, S. S. Chronic lithium treatment magnifies learning in rats. Neuroscience 150, 774-788, https://doi.org/10.1016/j.neuroscience.2007.09.063 (2007).

66. Tsaltas, E. et al. Enhancing effects of chronic lithium on memory in the rat. Behav Brain Res 177, 51-60, https://doi.org/10.1016/j. bbr.2006.11.003 (2007)

67. Tsaltas, E., Kyriazi, T., Poulopoulou, C., Kontis, D. \& Maillis, A. Enhancing effects of lithium on memory are not by-products of learning or attentional deficits. Behav Brain Res 180, 241-245, https://doi.org/10.1016/j.bbr.2007.03.017 (2007).

68. Lipina, T. et al. Inhibition of glycogen synthase kinase 3 prevents synaptic long-term depression and facilitates cogition in C57BL/6 mice. Opera Medica et Physiologica 2, 14 (2016).

69. King, M. K. et al. Glycogen synthase kinase-3 inhibitors: Rescuers of cognitive impairments. Pharmacol Ther 141, 1-12, https://doi. org/10.1016/j.pharmthera.2013.07.010 (2014).

70. Lovestone, S. et al. A phase II trial of tideglusib in Alzheimer's disease. J Alzheimers Dis 45, 75-88, https://doi.org/10.3233/JAD141959 (2015).

71. Du, J. et al. A kinesin signaling complex mediates the ability of GSK-3beta to affect mood-associated behaviors. Proc Natl Acad Sci USA 107, 11573-11578, https://doi.org/10.1073/pnas.0913138107 (2010).

72. Belzung, C. Innovative drugs to treat depression: did animal models fail to be predictive or did clinical trials fail to detect effects? Neuropsychopharmacology 39, 1041-1051, https://doi.org/10.1038/npp.2013.342 (2014).

73. O’Donnell, J. M., Marek, G. J. \& Seiden, L. S. Antidepressant effects assessed using behavior maintained under a differentialreinforcement-of-low-rate (DRL) operant schedule. Neurosci Biobehav Rev 29, 785-798, https://doi.org/10.1016/j. neubiorev.2005.03.018 (2005).

74. Nollet, M., Le Guisquet, A. M. \& Belzung, C. Models of depression: unpredictable chronic mild stress in mice. Curr Protoc Pharmacol Chapter 5(Unit 5), 65, https://doi.org/10.1002/0471141755.ph0565s61 (2013).

75. Blanchard, D. C., Griebel, G. \& Blanchard, R. J. The Mouse Defense Test Battery: pharmacological and behavioral assays for anxiety and panic. Eur J Pharmacol 463, 97-116 (2003).

76. Devanand, D. P. et al. Low-dose Lithium Treatment for Agitation and Psychosis in Alzheimer Disease and Frontotemporal Dementia: A Case Series. Alzheimer Dis Assoc Disord 31, 73-75, https://doi.org/10.1097/WAD.0000000000000161 (2017).

77. Prickaerts, J. et al. Transgenic mice overexpressing glycogen synthase kinase 3beta: a putative model of hyperactivity and mania. J Neurosci 26, 9022-9029, https://doi.org/10.1523/JNEUROSCI.5216-05.2006 (2006)

78. Miller, J. S., Tallarida, R. J. \& Unterwald, E. M. Cocaine-induced hyperactivity and sensitization are dependent on GSK3. Neuropharmacology 56, 1116-1123, https://doi.org/10.1016/j.neuropharm.2009.03.006 (2009).

79. Xu, C. M. et al. Glycogen synthase kinase 3beta in the nucleus accumbens core mediates cocaine-induced behavioral sensitization. J Neurochem 111, 1357-1368, https://doi.org/10.1111/j.1471-4159.2009.06414.x (2009).

80. Xu, C. M. et al. Glycogen synthase kinase 3 beta in the nucleus accumbens core is critical for methamphetamine-induced behavioral sensitization. J Neurochem 118, 126-139, https://doi.org/10.1111/j.1471-4159.2011.07281.x (2011).

81. Enman, N. M. \& Unterwald, E. M. Inhibition of GSK3 attenuates amphetamine-induced hyperactivity and sensitization in the mouse. Behav Brain Res 231, 217-225 (2012).

82. Creese, I. \& Iversen, S. D. The role of forebrain dopamine systems in amphetamine induced stereotyped behavior in the rat. Psychopharmacologia 39, 345-357 (1974).

83. Kelly, P. H., Seviour, P. W. \& Iversen, S. D. Amphetamine and apomorphine responses in the rat following 6-OHDA lesions of the nucleus accumbens septi and corpus striatum. Brain Res 94, 507-522 (1975). 
84. Balla, A., Sershen, H., Serra, M., Koneru, R. \& Javitt, D. C. Subchronic continuous phencyclidine administration potentiates amphetamine-induced frontal cortex dopamine release. Neuropsychopharmacology 28, 34-44, https://doi.org/10.1038/sj. npp.1300019 (2003).

85. Ren, J., Xu, H., Choi, J. K., Jenkins, B. G. \& Chen, Y. I. Dopaminergic response to graded dopamine concentration elicited by four amphetamine doses. Synapse 63, 764-772, https://doi.org/10.1002/syn.20659 (2009).

86. Jessen, F. et al. Sensory gating deficit expressed by a disturbed suppression of the P50 event-related potential in patients with Alzheimer's disease. Am J Psychiatry 158, 1319-1321, https://doi.org/10.1176/appi.ajp.158.8.1319 (2001).

87. Hejl, A. M., Glenthoj, B., Mackeprang, T., Hemmingsen, R. \& Waldemar, G. Prepulse inhibition in patients with Alzheimer's disease. Neurobiol Aging 25, 1045-1050, https://doi.org/10.1016/j.neurobiolaging.2003.11.005 (2004).

88. Cancelli, I. et al. Sensory gating deficit assessed by $\mathrm{P} 50 / \mathrm{Pb}$ middle latency event related potential in Alzheimer's disease. J Clin Neurophysiol 23, 421-425, https://doi.org/10.1097/01.wnp.0000218991.99714.ee (2006).

89. Bender, S. et al. Auditory post-processing in a passive listening task is deficient in Alzheimer's disease. Clin Neurophysiol 125, 53-62, https://doi.org/10.1016/j.clinph.2013.05.026 (2014).

90. Reichert, M. et al. Sensory and Behavioral Responses of a Model Fish to Oil Sands Process-Affected Water with and without Treatment. Environ Sci Technol 51, 7128-7137, https://doi.org/10.1021/acs.est.7b01650 (2017).

91. Braff, D. L. \& Geyer, M. A. Sensorimotor gating and schizophrenia. Human and animal model studies. Arch Gen Psychiatry 47, 181-188 (1990)

92. Wang, H. et al. Sensorimotor gating and memory deficits in an APP/PS1 double transgenic mouse model of Alzheimer's disease. Behav Brain Res 233, 237-243, https://doi.org/10.1016/j.bbr.2012.05.007 (2012).

93. Depoortere, R., Perrault, G. \& Sanger, D. J. Potentiation of prepulse inhibition of the startle reflex in rats: pharmacological evaluation of the procedure as a model for detecting antipsychotic activity. Psychopharmacology (Berl) 132, 366-374 (1997).

94. Svenningsson, P. et al. Diverse psychotomimetics act through a common signaling pathway. Science 302, 1412-1415, https://doi. org/10.1126/science.1089681 (2003).

95. Lipina, T. V. et al. Genetic and pharmacological evidence for schizophrenia-related Disc1 interaction with GSK-3. Synapse 65, 234-248, https://doi.org/10.1002/syn.20839 (2011).

96. Chen, Y. W. \& Lai, W. S. Behavioral phenotyping of v-akt murine thymoma viral oncogene homolog 1-deficient mice reveals a sexspecific prepulse inhibition deficit in females that can be partially alleviated by glycogen synthase kinase- 3 inhibitors but not by antipsychotics. Neuroscience 174, 178-189, https://doi.org/10.1016/j.neuroscience.2010.09.056 (2011).

97. Thompson, S. L. \& Dulawa, S. C. Dissecting the roles of beta-arrestin2 and GSK-3 signaling in 5-HT1BR-mediated perseverative behavior and prepulse inhibition deficits in mice. PLoS One 14, e0211239, https://doi.org/10.1371/journal.pone.0211239 (2019).

98. Kapfhamer, D. et al. Protein Phosphatase 2a and glycogen synthase kinase 3 signaling modulate prepulse inhibition of the acoustic startle response by altering cortical M-Type potassium channel activity. J Neurosci 30, 8830-8840, https://doi.org/10.1523/ JNEUROSCI.1292-10.2010 (2010).

\section{Acknowledgements}

The expert technical assistance of Carmen Aliaga, Sophie Ho-Van Guimbal, Martine Lacave, Claudine Leonardon, Marie-Thérèse Lucas and Alexandre Urani was highly appreciated.

\section{Author contributions}

G.G. drafted and approved the final version of the manuscript; A.M., D.B., F.S., G.B., J.E., J.S., M.F., M.L.G., P.P., S.B. and S.T. reviewed the manuscript and conceived and/or designed the work that led to the submission, acquired data, and/or played an important role in interpreting the results.

\section{Competing interests}

Organizations from whom the authors have received compensation for professional services: Guy Griebel, employee of Sanofi; Jeanne Stemmelin, employee of Sanofi; Mati Lopez-Grancha, employee of Sanofi; Denis Boulay, employee of Sanofi; Gérald Boquet, employee of Sanofi; Franck Slowinski, employee of Sanofi; Philippe Pichat, employee of Sanofi; Sandra Beeské, employee of Sanofi; Shinji Tanaka, employee of Mitsubishi Tanabe Pharma Corporation; Akiko Mori, employee of Mitsubishi Tanabe Pharma Corporation; Masatake Fujimura, employee of Mitsubishi Tanabe Pharma Corporation; Junichi Eguchi, employee of Mitsubishi Tanabe Pharma Corporation.

\section{Additional information}

Supplementary information is available for this paper at https://doi.org/10.1038/s41598-019-54557-5.

Correspondence and requests for materials should be addressed to G.G.

Reprints and permissions information is available at www.nature.com/reprints.

Publisher's note Springer Nature remains neutral with regard to jurisdictional claims in published maps and institutional affiliations.

Open Access This article is licensed under a Creative Commons Attribution 4.0 International License, which permits use, sharing, adaptation, distribution and reproduction in any medium or format, as long as you give appropriate credit to the original author(s) and the source, provide a link to the Creative Commons license, and indicate if changes were made. The images or other third party material in this article are included in the article's Creative Commons license, unless indicated otherwise in a credit line to the material. If material is not included in the article's Creative Commons license and your intended use is not permitted by statutory regulation or exceeds the permitted use, you will need to obtain permission directly from the copyright holder. To view a copy of this license, visit http://creativecommons.org/licenses/by/4.0/.

(c) The Author(s) 2019 